\title{
Removal Properties of Anionic Dye Eosin by Cetyltrimethylammonium Organo-Clays: The Effect of Counter-Ions and Regeneration Studies
}

\author{
Fethi Kooli ${ }^{1, *(1)}$, Yan Liu ${ }^{2}$, Mostafa Abboudi ${ }^{3}$, Souad Rakass ${ }^{3}$, Hicham Oudghiri Hassani ${ }^{3,4}$, \\ Sheikh Muhammad Ibrahim ${ }^{3}$ and Rawan Al-Faze ${ }^{3}$ \\ 1 Community College, Taibah University-Al-Mahd Branch, Al-Mahd 42112, Saudi Arabia \\ 2 Institute of Chemical and Engineering Sciences, 1 Pesek Road, Jurong Island, Singapore 627833, Singapore; \\ liu_yan@ices.a-star.edu.sg \\ 3 Department of Chemistry, Taibah University, P.O. Box 30002, Al-Madinah Al-Munawwarah 41147, \\ Saudi Arabia; abboudi14@hotmail.com (M.A.); rakass_souad@yahoo.fr (S.R.); \\ oudghiri_hassani_hicham@yahoo.com (H.O.H.); mdibrahi@gmail.com (S.M.I.); \\ rawan.faze@gmail.com (R.A.-F.) \\ 4 Département de Chimie, Faculté des Sciences Dhar El Mahraz, Université Sidi Mohamed Ben Abdellah, \\ B. P. 1796 (Atlas), Fès 30003, Morocco \\ * Correspondence: fkooli@taibahu.edu.sa; Tel.: +96-65-6944-2963
}

Received: 19 August 2018; Accepted: 11 September 2018; Published: 15 September 2018

\begin{abstract}
The organo-clays (OCs) were prepared by a cation exchange reaction between surfactant (cetyltrimethylammonium, C16TMA) from different counterions (Bromide, Chloride, and Hydroxide). The effect of the counterions was investigated on the physico-chemical properties of the prepared organo-clays. The highest uptake of organic cations $(1.60 \mathrm{mmol} / \mathrm{g})$ was achieved using cetyl trimethylammonium bromide solution and the lowest value $(0.93 \mathrm{mmol} / \mathrm{g})$ was obtained after modification with cetyl trimethylammonium hydroxide solution starting from the same initial ratio of mmol/g of clay greater than 2.40. The arrangement of C16TMA cations within the interlayer space was assumed to be perpendicular with a tilt angle of $32^{\circ}$ to the plane of clay sheets instead of being parallel to the clay surface using C16TMAOH solution at the same ratio. Different techniques were used to characterize these materials. The thermal stability of these organ-clays was investigated using an in-situ X-ray diffraction (XRD) technique. The decomposition of the surfactant moiety occurred at temperatures higher than $215^{\circ} \mathrm{C}$ and was accompanied with a shrinkage of the basal spacing value to $1.42 \mathrm{~nm}$. These materials were applied in the removal of an acid dye "eosin." The removed amount of eosin depended on the initial concentrations and the content of surfactants in the organo-clays. The removal of eosin was found to be an endothermic process. The maximum amount of $90 \mathrm{mg} / \mathrm{g}$ was achieved. The preheated treatment temperature of two selected OCs did affect the removal properties of eosin. A progressive reduction was observed at temperatures higher than $200{ }^{\circ} \mathrm{C}$. The regeneration of spent OCs was studied and acceptable removal efficiency was maintained after 4 to 6 cycles depending on the used initial concentrations.
\end{abstract}

Keywords: cetyltrimethylammonium cations; organo-clays; counter-ions; exchange reaction; in-situ $\mathrm{XRD}$; anionic dye; eosin dye; removal; regeneration

\section{Introduction}

Currently, the organoclays (OCs) are attracting a lot of interest either in the academic field or in their wide applications in different industrial areas due to their availability on a large scale such as paints, rheological control agents, grease, personal care, oil well drilling, polymer nanocomposites, etc. [1-3]. 
One of the major applications of these materials is an environmental application and, especially in the polluted water treatment, they are used as an adsorbent or removal agent of neutral organic compounds [4,5] and colorant dyes [6]. The hydrophilic character of clay minerals was modified by surfactants with different chemical structures. The surface nature is changed from hydrophilic to organophilic and these materials have an affinity to non-polar molecules and others [7]. The OCs are generally prepared from clay minerals that belong to 2:1 type (smectite group) due to their high swelling capacities. This property was related to the interlayer small cations and their easy hydration [8]. When clay is in contact with water, these charge-compensating cations can be exchanged or replaced by others present in the bulk of the suspension [5]. The negative surface charge of clay minerals was created by the isomorphous substitution of $\mathrm{Al}^{3+}$ for $\mathrm{Si}^{4+}$ in the tetrahedral layer and $\mathrm{Mg}^{2+}$ for $\mathrm{Al}^{3+}$ in the octahedral layer [5]. The properties of clay minerals that makes it ideal for the preparation of OCs are the high surface area and the surface charge. The quaternary alkyl ammonium cations (QACs) are the preferred surface modifiers due to their low cost and easier processing [9]. QACs cations are composed of a nitrogen head group and four exchangeable positions that can be occupied by organic functional groups with different structures and sizes [10].

OCs are usually divided into two groups depending on the length of QACS and the sorption mechanism. The first group is the adsorptive OCs that consist of short chain quaternary ammonium ion $(\mathrm{R}<12)$ such as TMA (tetramethyl ammonium) and TBA (tetrabenzyl ammonium). The second type of OCs is organophilic clays, which consists of a long chain quaternary ammonium ion $(R>12)$ such as HDTMA (hexadecyl trimethyl ammonium) and ODTMA (octadecyl trimethyl ammonium [11]. The properties of the OCs can be engineered and depended mainly on the choice of the clay minerals, the cation exchange capacity (CEC), and the structure of the surfactants. It has been found that the structure and chemical characteristics of the clay mineral have a strong effect on the cation exchange that is involved in the synthesis of the OCs [12]. Usually the cation exchange reaction starts at the edges of clay particles and then extends to the center. Kinetic studies show that the reaction between the quaternary ammonium salts and the clay mineral improves with the increased temperature [13]. The literature survey indicated that the frequently used alkyl ammonium cations is the cetyl trimethylammonium or hexadecyl trimethyl ammonium (C16TMA) with an alkyl chain of 16 carbons and bromide as an anion. The resulting OCs were prepared from C16TMABr solutions at different concentrations and conditions [14].

Few studies have reported the use of cetyl trimethyl ammonium chloride [15-17]. The counterions affected the critical micelle concentration $(\mathrm{cmc}$ ) of the surfactant solution. The C16TMABr solution has a cmc value of $0.94 \mathrm{mM}$ lower than the $\mathrm{cmc}$ of $\mathrm{C} 16 \mathrm{TMACl}(1.4 \mathrm{mM})$ in deionized water due to the smaller counterion $\mathrm{Br}^{-}$compared to the $\mathrm{Cl}^{-}$counter ion [18]. These anions also affected the micelle sphere to rod transition in solution [19], the interaction between the cationic surfactants, and the anionic dyes. [20]. The higher $\mathrm{pH}$ values of the surfactant solution have affected the exfoliation properties of a particular acid-activated clay mineral. [21]. The use of C16TMAOH solution was undertaken for further studies and interesting data were obtained using acid-activated layered silicates such as clay mineral and protonated magadiite [22,23]. The content of the surfactants cations was improved in the resulting organo-acid activated clays and organo-magadiites [22,23].

Our interest is to use these OCs to remove acidic dyes. The acidic dyes exhibited a negative charge, which make it difficult to be adsorbed on the negatively charged surfaces of clay minerals and other silicate materials due to the electrostatic repulsion [24,25]. Similar observations were reported in case of some agricultural waste materials and the surface modification was able to enhance the affinity of these materials towards anionic dyes. The cationic surfactant $\left(\mathrm{C}^{2} \mathrm{TMA}^{+}\right)$was proposed as the modifying agent for the previously mentioned purpose [26,27].

In this study, the effect of the counter-ions on the intercalation of C16TMA cations was investigated by selecting a clay mineral with higher cation exchange capacity. The synthesis and characterization of the resulting OCs were undertaken by different techniques. The thermal stability of selected OCs based on their organic contents was investigated in-situ X-ray diffraction (means atreal temperatures during 
the collection of the patterns without cooling down the samples). This part will give an insight about the structural changes in the interlayer spacing and how they might affect the removal properties of an anionic dye "eosin." The eosin was chosen as a model pollutant because of its variety of usage. It is mainly used in silk, wool, modified acrylic, polyamide, propylene fibers, in pharmaceutical industry, etc. $[28,29]$. The eosin molecule carries aromatic and sulphonic groups that make these dyes harmful to human and other microorganisms [30]. Different parameters were investigated as well as their effect on the eosin removal such as removal temperature, initial concentrations, and the preheated temperatures of selected OCs.

\section{Experimental Part}

\subsection{Materials}

A polymer grade montmorillonite (PG) used in this study was obtained from Nanocorcompany (Hoffman Estates, IL, USA) and used without any treatment. Its cation exchange capacity (CEC) value about $145 \mathrm{meq} / \mathrm{g}$ as mentioned by the supplier. Cetyl trimethylammonium hydroxide solution (C16TMAOH) was purchased from TCI, Singapore, C16TMABr, C16TMACl solid salts and eosin dye were obtained from Acros Organics (Loughborough, UK) and were used without any purification. Figure 1 presents the chemical structure of the used eosin dye.<smiles></smiles>

Figure 1. Chemical structure of the eosin $Y$ dye.

\subsection{Synthesis of OCs}

OCs were prepared by a cation exchange reaction [31]. The QACs (known amounts) were dissolved into $25 \mathrm{~mL}$ of deionized water.Then $1.0 \mathrm{~g}$ of PG clay was poured to the QAC solution and stirred overnight at room temperature. The solution was filtrated and the resulting OCs were washed several times with deionized water and then dried at room temperature overnight.

For comparison purposes, the same molar amounts of C16TMA cations from different sources were used and the corresponding amount of the salt was dissolved in $25 \mathrm{~mL}$ of deionized water. Whenever necessary to completely dissolve the surfactants, the solution was gently heated at $50{ }^{\circ} \mathrm{C}$. The OCs were prepared using the same procedure described above. The resultant modified PG clay were denoted as C16XPG-Y where $\mathrm{X}$ is the counterion of the used surfactant solution and $\mathrm{Y}$ is the initial loading concentration of surfactant in $\mathrm{mmol} / \mathrm{g}$ (basis).

\subsection{Effect of Washing Solution}

Selected organo-clay (C16BrPG-2.40) was prepared from the C16TMABr solution and, using a loading concentration of $2.40 \mathrm{mmol}$ dissolved into $25 \mathrm{~mL}$ after the exchange reaction, the solid was collected by filtration and washed by $100 \mathrm{~mL}$ mixture of ethanol and water at different compositions. Then it was dried at room temperature.

\subsection{Eosin Removal Experiment}

The removal of eosin was carried out using batch mode experiments, as reported previously [32]. A fixed amount of OC $(0.1 \mathrm{~g})$ was added to $10 \mathrm{~mL}$ of known concentrations in a series of $12 \mathrm{~mL}$ 
closed tubes. The used solutions varied from 25 to $1200 \mathrm{mg} / \mathrm{L}$ and were prepared by dilution from a stock solution (of $1500 \mathrm{mg} / \mathrm{L}$ ). The tubes were shaken at $130 \mathrm{rpm}$ at $25{ }^{\circ} \mathrm{C}$ for overnight. After centrifugation, the amounts of the un-removed dye in the supernatant solutions were analyzed for its dye concentration using a double beam UV-vis spectrophotometer. All measurements were done at the maximum absorbance at the wavelength of $610 \mathrm{~nm}$.

The removal experiments were conducted by varying initial eosin concentration, temperature of the removal process, and the preheat treatment of selected OCs prior to the eosin removal.

\subsection{Regeneration/Removal Cycles}

Fresh OC samples were mixed with eosin solution $\left(C_{i}=200 \mathrm{mg} / \mathrm{L}\right)$. After the removal process, the sample was separated by centrifugation. The spent material was treated in an aqueous solution of oxone and cobalt nitrate [33]. The oxone was used as an oxidant and $\mathrm{Co}^{2+}$ ions were utilized as a catalyst after separation. The treated solid was added to a fresh dye solution for removal in the succeeding cycle. The same procedure was undertaken for the cycle.

\subsection{Characterization Methods}

The $d_{001}$ spacing of the OCs were estimated from the first 001 reflections in the powder X-ray diffraction patterns and recorded in a Bruker Advance 8 equipped with a Copper anode $(\mathrm{Cu} \mathrm{K} \alpha=1.5418 \AA$ ). A EURO EA elemental analyser was employed to determine the amount of C16TMA cations taken up by the different samples. Two parallel runs for each sample were performed.

The thermogravimetric analysis was carried out on a TGA/DTA system (TA instrument, model 2690) form RT to $900^{\circ} \mathrm{C}$ at a heating rate of $10^{\circ} \mathrm{C} / \mathrm{min}$ under the air atmosphere. The nitrogen isotherms adsorption was performed on a Micromeritcs ASAP 2040 instrument. The samples were treated at $100{ }^{\circ} \mathrm{C}$ under vacuum prior to the measurement. The BET equation was used to estimate the specific surface areas. The pore volume was deduced at a relative pressure $\left(\mathrm{P} / \mathrm{P}_{\mathrm{o}}\right)$ value of 0.95 . The solid ${ }^{13} \mathrm{C} C P$ NMR technique was performed to investigate the conformation of the intercalated C16TMA cations. The detail analysis was reported in our previous work [21].

The powder in-situ X-ray diffraction runs were performed using a HTK 16 high temperature chamber (Anton Paar) mounted on a Bruker AXS, D8 Advance diffractometer. The temperature varied in the range of $25^{\circ} \mathrm{C}$ to $420^{\circ} \mathrm{C}$. UV-VIS spectrophotometer from Varian (carry 100) was used to estimate the absorbance at maximum wavelength $\left(\lambda_{\max }=610 \mathrm{~nm}\right)$ in the supernatant and computed from the calibration curves.

\section{Results and Discussion}

\subsection{Elemental Analysis}

The $\mathrm{C}, \mathrm{H}, \mathrm{N}$ elemental analysis was employed to estimate the up take (real) amount of C16TMA cations in the OCs. The data are presented in Table 1. For an initial loading concentration of $2.40 \mathrm{mmol}$ (corresponded to initial CEC/mmol of C16TMA ratio of 1.65), the highest content $(39.23 \%$ ) was obtained when C16TMABr solution was used, and the lowest one (19.01\%) was achieved starting from C16TMAOH solution. Using the chloride solution, an intermediate value of $30.77 \%$ was attained.

Table 1. C, H, N elemental analysis of different OCs prepared at different conditions.

\begin{tabular}{ccccc}
\hline Samples & $\mathbf{C} \%$ & $\mathbf{H} \%$ & $\mathbf{N} \%$ & Up Take Amount $(\mathbf{m m o l} / \mathbf{g}){ }^{*}$ \\
\hline C16BrPG-2.40 & 39.23 & 5.88 & 2.34 & 1.60 \\
C16ClPG-2.40 & 30.77 & 4.88 & 1.96 & 1.26 \\
C16OHPG-2.40 & 18.91 & 3.60 & 1.69 & 0.93 \\
\hline
\end{tabular}

* Up take amount $=\mathrm{C}(\%) /[(12 \times($ number of carbon atom in CTMA $)] \times 1000$. 
The up take amount of C16TMA cations was higher than the CEC from Br solution. Then it dropped to $86 \%$ and $64 \%$ for $\mathrm{Cl}$ and $\mathrm{OH}$ solutions. Attempts have been carried out to improve the content of $\mathrm{C} 6 \mathrm{TMA}^{+}$cations from hydroxide solution by increasing the initial loading concentrations higher than $2.40 \mathrm{mmol}$. However, the up take amount was unchanged. Similar data were obtained for another type of clay mineral with low cation exchange capacity (CEC) [34].

Using a C16TMABr solution, the up take amount was tuned by changing the initial loading concentrations below $2.40 \mathrm{mmol}$. The data are presented in Figure 2. All the C16TMA cations initially loaded were taken up by the PG clay mineral for the initial ratios CEC to mmol close to 1 (Y values less than 1.65). At higher ratios, the experimental up take values were higher than the CEC values but are still lower than the theoretical values (Figure 1).

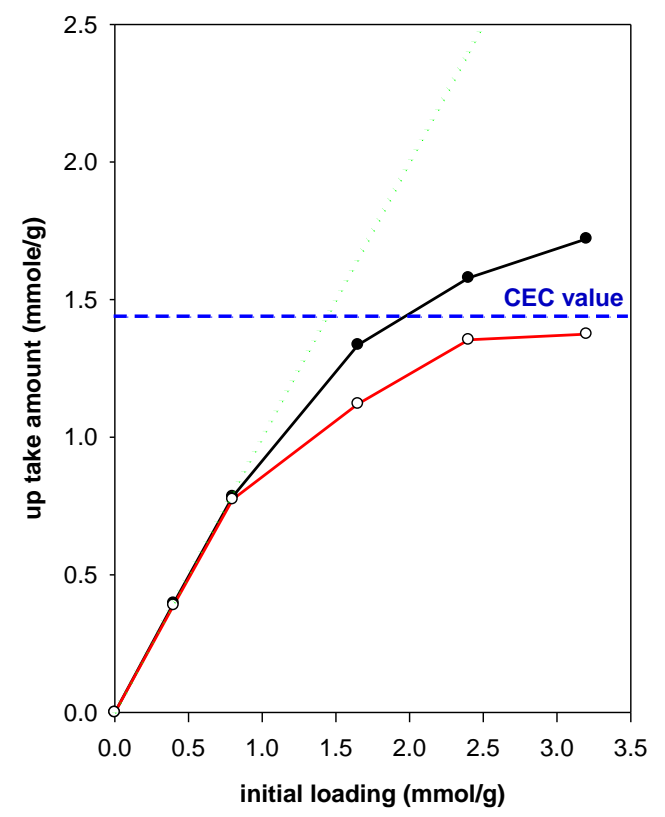

Figure 2. The uptake amount of C16TMA cations by the PG clay as a function of initial loading concentrations using C16TMABr solution.

These data indicated that the mechanism of C16TMA uptake using bromide solution was different than the hydroxide one. The later one was mainly based on a cation exchange reaction. However, using Br solution, an additional mechanism happened and could be related to the hydrophobic interaction between the surfactant molecules [35].

This mechanism was modified by using the same initial loading concentration (sample C16BrPG-2.40) and by washing the resulting OC by different mixtures of ethanol and water. The $C, H$, $\mathrm{N}$ analysis are summarized in Table 2 and indicated that the content of the surfactants in the obtained OCs decreased when it was washed with a mixture of ethanol and water even at a low percentage of ethanol of $25 \%$. Similar observations were noted when using a mixture of ethanol and water as a reaction medium instead of pure deionized water $[21,36,37]$.

Table 2. C, H, N analysis of C16BrPG-2.40 after washing with different mixtures of ethanol and water.

\begin{tabular}{ccccc}
\hline Samples & $\mathbf{C} \%$ & $\mathbf{H} \%$ & $\mathbf{N} \%$ & Up Take Amount (mmol/g) \\
\hline C16BrPG-2.40 & 39.23 & 5.88 & 2.34 & 1.60 \\
25\% ethanol * & 20.52 & 4.40 & 1.22 & 0.90 \\
$50 \%$ ethanol * & 19.55 & 4.87 & 1.06 & 0.85 \\
75\% ethanol * & 18.76 & 4.54 & 1.01 & 0.82 \\
\hline
\end{tabular}

* Washed with a mixture of ethanol and water (\% in volume). 


\subsection{Powder XRD Data}

The powder XRD patterns of the starting PG clay and its organo-derivatives prepared from different surfactant solutions at a fixed initial loading concentration of $2.4 \mathrm{mmol} / \mathrm{g}$ of clay (basis) are depicted in Figure 3.

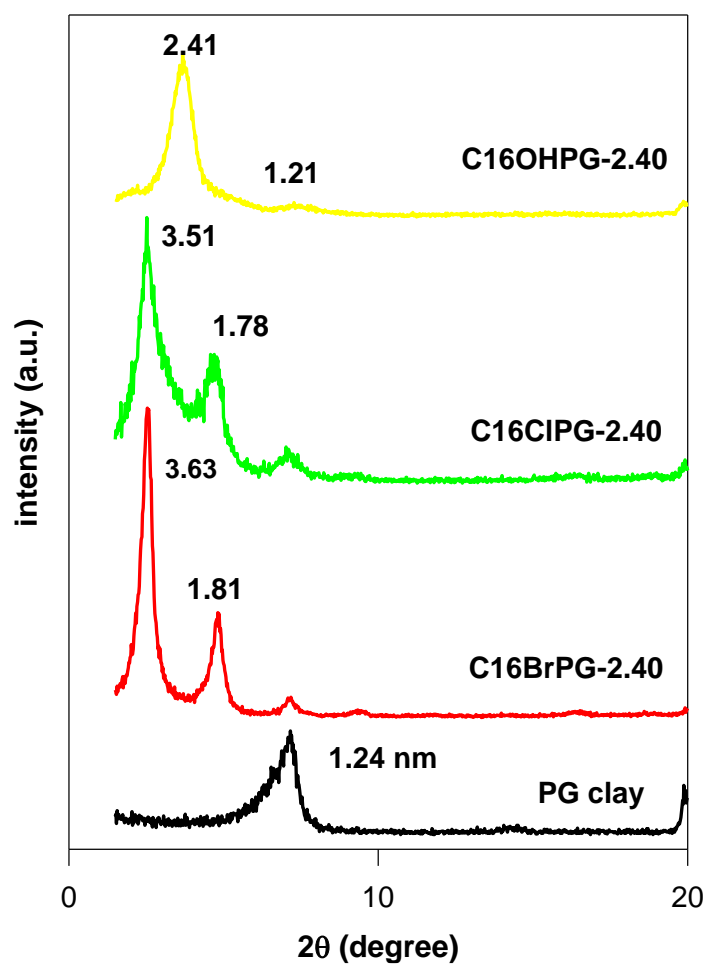

Figure 3. Powder XRD patterns of PG clay and its OCs prepared from different C16TMAX solutions.

The PG clay exhibited a 001 reflection at a basal spacing $\left(\mathrm{d}_{001}\right)$ of $1.24 \mathrm{~nm}$, which indicated that the raw sample is Na-montmorillonite with a monolayer of water molecules between the clay sheets [38,39]. After modification with surfactant solutions, a shift of the 001 reflection was observed to lower 2theta values and confirmed the intercalation of the surfactant cations in thePG interlayer spacing. The values of $\mathrm{d}_{001}$ increased from $1.24 \mathrm{~nm}$ to $3.63 \mathrm{~nm}$ and $3.51 \mathrm{~nm}$ when using C16TMABr and C16TMACl solutions. However, a lower value of $2.41 \mathrm{~nm}$ was obtained from a C16TMAOH solution. This observation indicated that the variation of $\mathrm{d}_{001}$ values was related to different contents of C16TMA cations, which is mentioned in Table 1 [31,35].

Many attempts were performed to increase the basal spacing ( $\mathrm{d}_{001}$ value) of C16OHPG-2.40 by using different initial loading concentrations for lower concentrations than $2.40 \mathrm{mmol}$. No variation of the basal spacing was observed and even at higher concentrations close to $20 \mathrm{mmol}$ (Figure S1), similar data were obtained for another clay mineral with lower CEC value $(0.96 \mathrm{meq} / \mathrm{g})$ [40]. However, using an acid activated clay mineral, a basal spacing of $3.83 \mathrm{~nm}$ was achieved at the same loading concentration of $2.40 \mathrm{mmol}$. This difference was related to different mechanisms of C16TMA intercalation [22].

The basal spacing of the OC prepared from C16TMABr solution was tuned by changing the initial loading concentrations. Figure 4 shows the PXRD patterns of the obtained materials. 


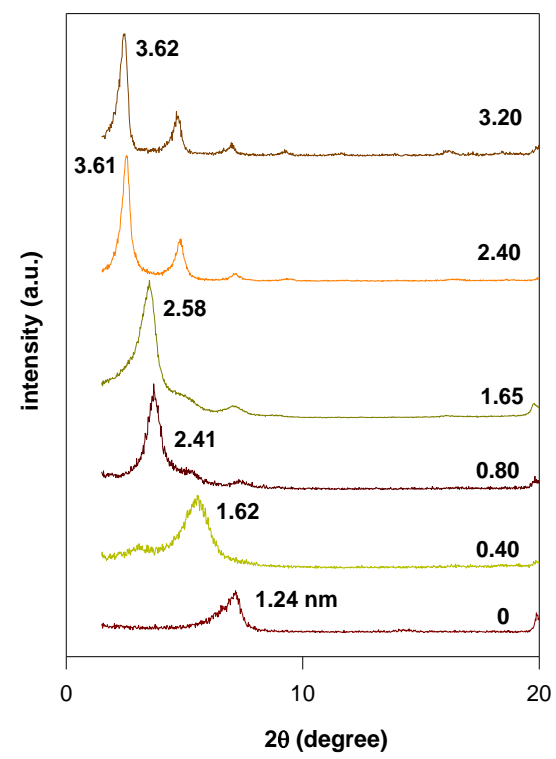

Figure 4. Powder XRD patterns of different OCs prepared from PG clay and C16TMABr solution at different initial loading concentrations $(\mathrm{mmol} / \mathrm{g})$.

The basal spacing of PG clay expanded gradually from $1.24 \mathrm{~nm}$ to $1.62 \mathrm{~nm}$ and $2.41 \mathrm{~nm}$ for initial concentrations lower than $2.40 \mathrm{mmol}$. Only one phase was obtained with $\mathrm{d}_{001}$ of $3.61 \mathrm{~nm}$ for C16TMA contents higher than $2.40 \mathrm{mmol}$. No further change of this value was noticed with regard to further increase of initial loading concentrations. Similar behavior was observed when the PG was modified with the $\mathrm{C} 16 \mathrm{TMACl}$ solution, which is a significant increase of the basal spacing from $2.47 \mathrm{~nm}$ to $3.49 \mathrm{~nm}$ at initial concentrations greater than $2.40 \mathrm{mmol}$. This variation was due to different orientations of C16TMA cations between the clay sheets. The changes in orientation of the intercalated C16TMA cations was related to the initial loading concentrations and, thus, to the up-take (real) amount intercalated between the clay sheets, as presented in Table 2.

However, this orientation was also related to the used exchange medium or to the washing solution [23]. Figure 5 presents the PXRD patterns of C16BrPG-2.40 washed with different ethanolic solutions (mixtures of ethanol/water in volume). The initial basal space of $3.88 \mathrm{~nm}$ was obtained during the washing process with pure deionized water. However, it shrank to $2.42 \mathrm{~nm}$ when it was washed with a mixture of $25 \%$ of ethanol and $75 \%$ of water. As the amount of ethanol increased in the washing solution, the position of the main peak practically does not change and the basal spacing was in the range of $2.39 \mathrm{~nm}$ to $2.36 \mathrm{~nm}$.

These data were in good agreement with the $\mathrm{C}, \mathrm{H}, \mathrm{N}$ elemental analysis. The decrease in the basal spacing was related to a change in the surfactants configuration between the clay sheets. However, the effect of the washing solution was not noticed for the sample with low C16TMA content. A slight shrinkage was observed, which indicates the stability of the surfactant orientation between the clay sheets. Similar observations were noticed for an OC prepared from acid-activated clay made from C16TMAOH solution with a basal spacing of $3.83 \mathrm{~nm}$ [21]. The decrease of the basal spacing was proposed to be related to the dissolution of the physically adsorbed surfactants and to rearrangements of the intercalated surfactants [41] or it could be related to a partial dissolution of surfactants located between the clay sheets due to the easy accessibility of the ethanol molecules to these surfactants [21]. 


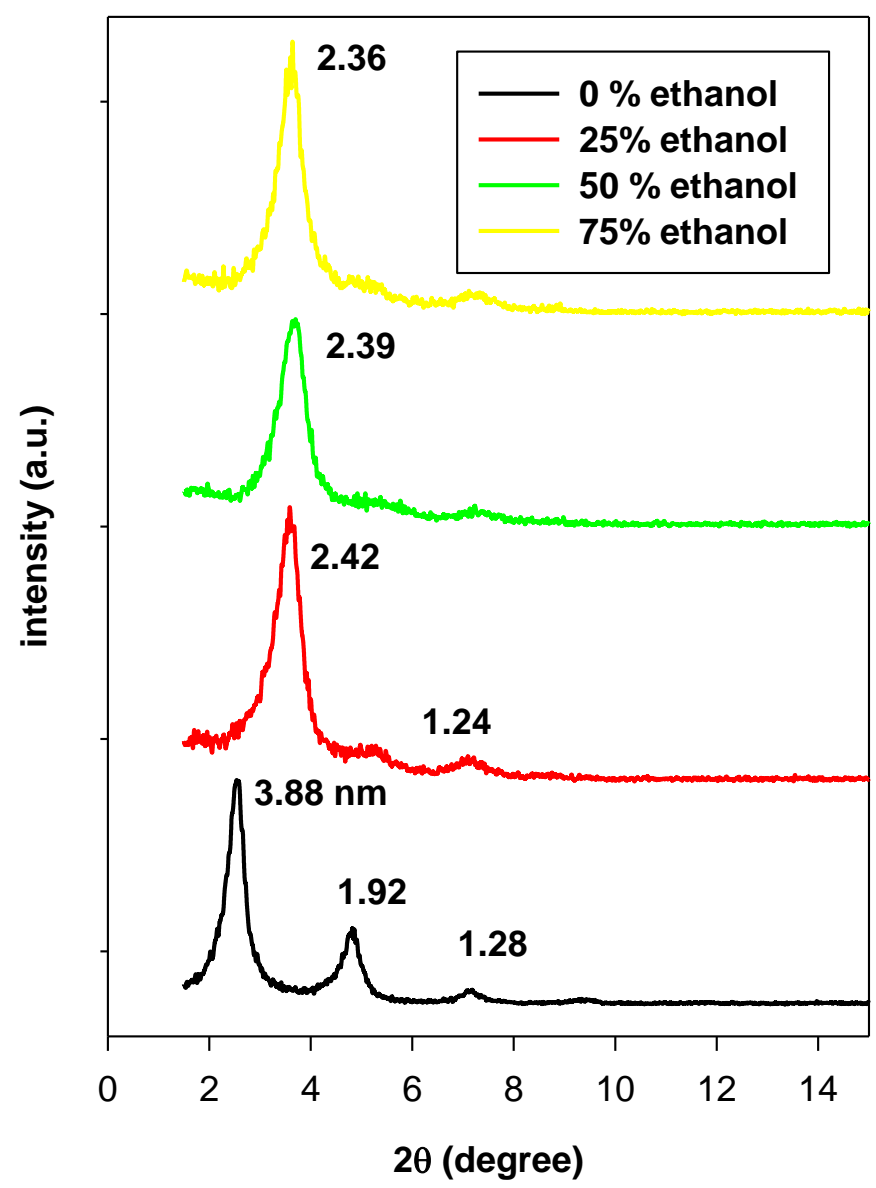

Figure 5. PXRD patterns of C16BrPG-2.40 washed with different aqueous ethanolic solutions (volume\%).

From the basal spacing values (deduced from $\mathrm{d}_{001}$ value) and the thickness of the silicate layer of $0.96 \mathrm{~nm}$ [42], the corresponding interlayer spacing are summarized in Table 3. The structure of C16TMA cations could be ascribed as a nail with the trimethyl ammonium as the head and the C16 aliphatic chain as the tail with a length of $2.38 \mathrm{~nm}$ [43] (Figure 6).

\section{$2.38 \mathrm{~nm}$}

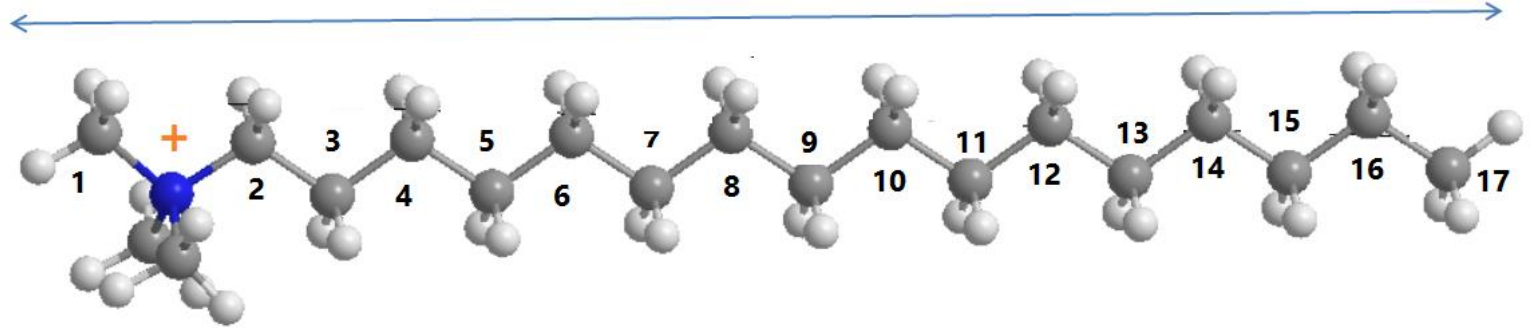

Figure 6. The optimized three-dimensional structural formula of the C16TMA cation.

The interlayer spacing of 2.55 to $2.65 \mathrm{~nm}$ correspond to a bilayer arrangement of C16TMA cations tilted of an angle of $32^{\circ}$ to $34^{\circ}$ (degrees) relative to the surface of the clay sheets. The interlayer distance of $1.46 \mathrm{~nm}$ corresponds to a monolayer with a tilted angle of $35^{\circ}$. Lan et al. [44] proposed a relation between the chain length of the alkylammonium ion and the basal spacing as $d_{001}=1.27 \times(n-1)+$ $d_{A}+r_{M}$. Where $(n-1)$ is the number of methylene groups in the onium ion chain, $d_{A}$ is the basal spacing for $\mathrm{NH}_{4}$-montmorillonite $(1.28 \mathrm{~nm}), \mathrm{r}_{\mathrm{M}}$ is the van der Waals radius of the methyl end group $(0.3 \mathrm{~nm})$, and $0.127 \mathrm{~nm}$ is the contribution due to the $-\mathrm{CH}_{2}$ - chain segments when the chain adopts an 
all-trans configuration. In this case, the $\mathrm{d}_{001}$ would be $4.22 \mathrm{~nm}$ for the bilayer paraffin rearrangement. This value was higher than the observed one $(3.61 \mathrm{~nm})$, which indicates that the C16TMA cations did not adopt a vertical all-trans configuration. However, a lateral bilayer of C16TMA cations was obtained when a mixture of ethanol/water was used as the washing solution due to lower content of C16TMA cations in this sample. Conceptual illustrations for the structure of organs-clays are depicted in Figure 7.

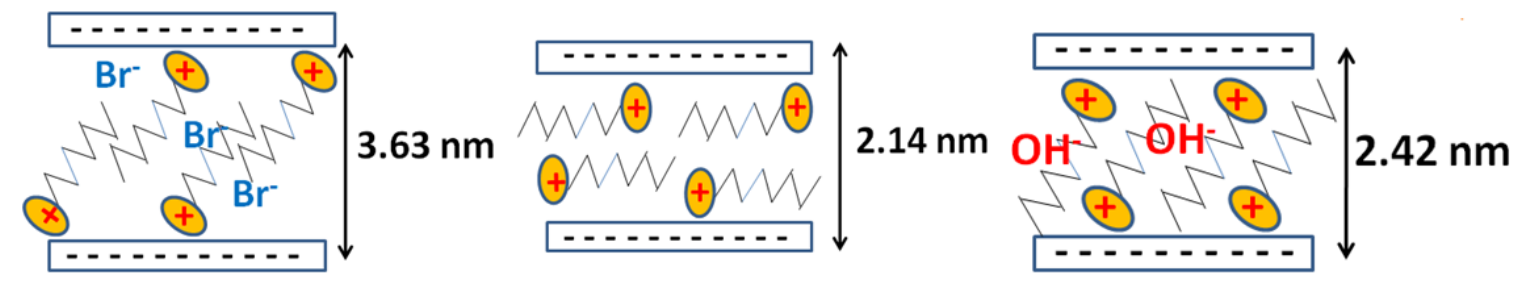

Figure 7. Illustrations of the structure of different organo-clays.

Table 3. The basal spacing values of OCs and possible arrangement of the intercalated C16TMA cations.

\begin{tabular}{cccc}
\hline Uploaded Amount & $\mathbf{d}_{\mathbf{0 0 1}}(\mathbf{n m})$ & Interlayer Spacing & Arrangement \\
\hline $0.40(\mathrm{Br})$ & 1.62 & 0.66 & Lateral monolayer \\
$0.80(\mathrm{Br})$ & 2.14 & 1.18 & Lateral bilayer \\
$1.65(\mathrm{Br})$ & 2.51 & 1.55 & Pseudo-trilayer \\
$2.40(\mathrm{Br})$ & 3.61 & 2.65 & Paraffin bilayer, $\theta=34^{\circ}$ \\
$3.20(\mathrm{Br})$ & 3.61 & 2.65 & Paraffin bilayer, $\theta=34^{\circ}$ \\
C16BrPG-2.40r & 3.61 & 2.65 & Paraffin bilayer, $\theta=34^{\circ}$ \\
C16ClPG-2.40 & 3.51 & 2.55 & Paraffin bilayer, $\theta=32^{\circ}$ \\
C16OHPG-2.40 & 2.42 & 1.46 & paraffin monolayer, $\theta=38^{\circ}$ \\
C16BrPG-2.40 * & 2.42 & 1.46 & or pseudo trilayer \\
\hline
\end{tabular}

${ }^{*}$ Washed with Ethanol/water mixture (50\% in volume).

\subsection{Solid ${ }^{13} C$ CP NMR Studies}

This technique is a powerful technique and it was used to probe the local environment and the conformation of the C16TMA cations between the interlayer spacing $[45,46]$. The ${ }^{13} \mathrm{C} \mathrm{CP}$ MAS resonance is sensitive to the difference in conformation and packing in addition to the chemical structure $[47,48]$. Figure 8 depicts the resonance spectra of the starting C16TMABr salt and OCs prepared from different solutions. The resonance spectrum of C16TMABr salt exhibits mainly one intense resonance peak at $33 \mathrm{ppm}$, which is assigned to the inner methylene $\left(C_{3}-C_{16}\right)$ units of C16TMA (Figure 8) indicating that the methylene carbons exhibited all-trans ( $t$ ) conformation [22] in addition to other resonances related to the C16TMABr salt [23] (see Table 4).

The ${ }^{13} \mathrm{C}$ CP NMR spectrum of the OC prepared from C16TMA hydroxide solution (C16OHPG-2.40) exhibited a resonance at $30 \mathrm{ppm}$ in addition to $33 \mathrm{ppm}$ one, corresponding to the disordered and the ordered conformation, respectively [49] (Figure 8). Similar spectrum was reported for OC prepared from different clay minerals from the same C16TMAOH solution [21,22], the other resonance peaks and their assignments are reported in Table 4 . The presence of the two resonance peaks indicated that the coexistence of all-trans $(t)$ and gauche $(g)$ conformations and confirmed the formation pseudo trilayer arrangement of the C16TMA cations or the paraffin monolayer arrangement between the clay sheets. The lateral bilayer arrangement gave rise to more gauche $(g)$ conformation compared to all trans $(t)$ one [47]. 


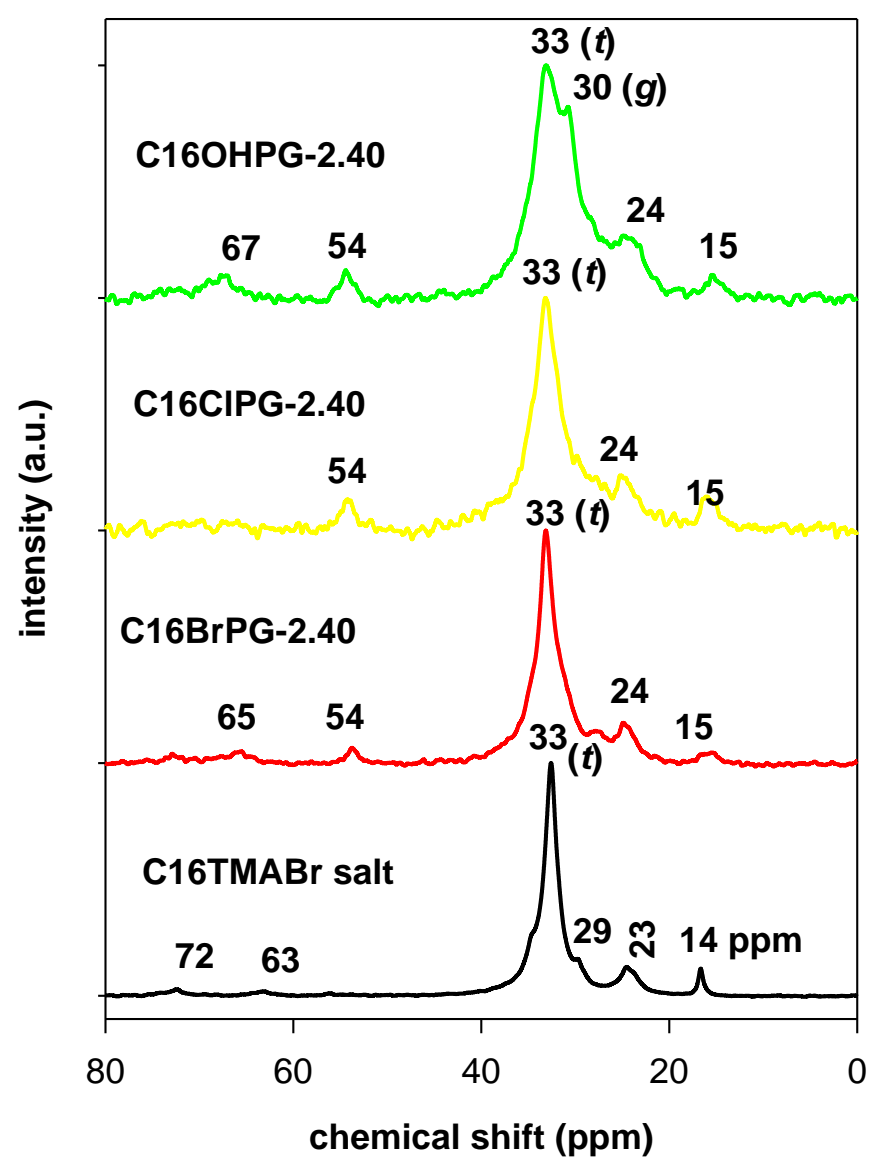

Figure 8. ${ }^{13} \mathrm{C} C P$ NMR spectrum of pure C16TMABr salt and the OCs prepared from different C16TMA solutions.

Qualitatively, the intensity of $(g)$ conformation decreased dramatically when the C16TMACl and C16TMABr solutions were used and the ${ }^{13} \mathrm{C} C P$ NMR exhibited mainly an intense resonance peak at 33 ppm similar to that of the pure C16TMABr salt, which is presented in Figure 8. The resonance peak at $30 \mathrm{ppm}$ was embedded in the intense peak as a shoulder and indicated that the C16TMA cations exhibited mainly all trans $(t)$ conformation due to the bilayer paraffin arrangement as indicated by the XRD technique [50]. In this arrangement, the trimethyl ammonuim heads were attached to the clay layers' surfaces, which induces a shift of the resonance peak at $16 \mathrm{ppm}$, and the tails of the surfactants were pulled away. This gives rise to the all trans $(t)$ conformation.

The estimated areas at the resonance peaks of 30 and $33 \mathrm{ppm}$ after deconvolution operation in the range of $24 \mathrm{ppm}$ to $50 \mathrm{ppm}$ were used to probe the disordered degree of indicated C16TMA cations (Figure S2) $[49,51]$. The fraction of gauche conformation $(g)$ was calculated as: $g /(g+t)=\mathrm{A}_{g} /\left(\mathrm{A}_{g}+\right.$ $\mathrm{A}_{t}$ ) where $\mathrm{A}_{g}$ and $\mathrm{A}_{t}$ are the integrated areas of the trans and gauche resonance peaks around 30 and $33 \mathrm{ppm}$. The fraction of gauche (0.15) was the lowest for the neat C16TMABr salt due to its crystalline order, which is supported by XRD data (see below). Then it increased for the intercalated surfactants with a maximum value of 0.48 for C16OHPG-2.40 sample and intermediate values of 0.38 and 0.24 for C16BrPG-2.40 and C16CIPG-2.40, respectively. The decrease of the gauche conformation was related to the transition of a liquidlike structure to semi-crystalline one with an increasing population of trans conformation [49]. 
Table $4 .{ }^{13} \mathrm{C}$ chemical shift (ppm) of C16TMA in bulk and in OCs.

\begin{tabular}{cccc}
\hline Carbon Atom & C16BrPG-2.40 & C16OHPG-2.40 & C16TMABr Solid \\
\hline$C_{2}$ & 65 & 67 & $63(67.05,64.55)$ \\
$C_{1}$ & 54 & 54 & $53(54.61)$ \\
$C_{15}$ & 35 & 35 & $35(36.40)$ \\
$C_{3}-C_{17}($ trans,$t)$ & 33 & 33 & $33(34.70)$ \\
$C_{3}-C_{17}$ (gauche, $\left.g\right)$ & 30 & 30 & $29(30.77-29.19)$ \\
$C_{2}, C_{16}$ & 24 & 24 & $23(23.12)$ \\
$C_{17}$ & 15 & 15 & $14(16.14,14.12)$ \\
\hline
\end{tabular}

Values between brackets are reported from Reference [52].

\subsection{Microtextural Properties}

Table 3 summarizes the specific surface area $\left(\mathrm{S}_{\mathrm{BET}}\right)$, pore volume, and average pore diameter of the starting PG clay and selected derived OCs. The PG clay exhibited a $S_{B E T}$ value of $67 \mathrm{~m}^{2} / \mathrm{g}$ close to that reported for similar clay minerals [53]. The organoclays exhibited a lower $\mathrm{S}_{\mathrm{BET}}$ in the range of 11 to $28 \mathrm{~m}^{2} / \mathrm{g}$. These values were close to that reported for similar materials [25,53,54] (Table 5).

Table 5. Textural properties of PG clay and its organo-derivatives prepared from surfactant solution with different counter anions. The $g$ conformation ratio was also presented.

\begin{tabular}{ccccc}
\hline Samples & $\mathbf{S}_{\text {BET }}\left(\mathbf{m}^{\mathbf{2}} \mathbf{g}\right)$ & P.V. $(\mathbf{c c} / \mathbf{g})$ & A.P.D $(\mathbf{n m})$ & $\mathbf{( g ) \text { Ratio Conformation }}$ \\
\hline PG-clay & 67.0 & 0.147 & 8.79 & - \\
C16BrPG-2.40 & 23.4 & 0.081 & 13.6 & 0.36 \\
C16ClPG-2.40 & 28.4 & 0.078 & 10.9 & 0.24 \\
C16OHPG-2.40 & 11.5 & 0.086 & 19.8 & 0.47 \\
\hline
\end{tabular}

The average pore size in the OCs was higher when compared to the starting PG-clay. This enhancement was related to the repulsion between the organo-clay particles. Qualitatively, the increase of the A.P.D. value was related to the gauche fraction conformation. The total pore volume (P.V.) of PG clay decreased after modification [54]. Most commonly, the cationic surfactant head groups carry positive charge and are tightly bonded to the clay surfaces. Consequently, all cationic surfactants are expected to cover some/all of the mineral surfaces and decrease the apparent surface area of the surfactant/clay hybrid. Cationic surfactant head groups reduce the inter-particle repulsive forces, can cause particles to aggregate, and, therefore, can also reduce the surface area [51,54-56].

\subsection{Thermogravimetric Analysis}

This technique was used to investigate the thermal stability of the OCs. The derivative thermogravimetric analysis (DTG) was performed to identify in more accuracy the temperature ranges on which the mass loss step occurs. The TGA/DTG features are presented in Figure 9. From the TG analysis, thermal decomposition of PG clay took place mainly in two steps while the thermal decomposition of the studied OCs occurred in three steps.

The PG clay exhibited a single mass of $15 \%$ from room temperature to $150{ }^{\circ} \mathrm{C}$ due to the removal of adsorbed water on the external surface and the dehydration of water molecules coordinated to $\mathrm{Na}^{+}$ cations, which are associated with two peaks at $50{ }^{\circ} \mathrm{C}$ and $84{ }^{\circ} \mathrm{C}$, respectively [57]. A second mass of $3.7 \%$ at higher temperature ranges from $500{ }^{\circ} \mathrm{C}$ to $700{ }^{\circ} \mathrm{C}$ was attributed to the dehydroxylation of the clay sheets with a maximum temperature loss of $648^{\circ} \mathrm{C}$ [57] (Figure 9). The OC (C16BrPG-2.40) exhibited additional mass loss that began at $170{ }^{\circ} \mathrm{C}$ (from DTG curve), which indicates the starting and the progressive elimination of the organic part in $\mathrm{OC}$, and it ended at $400{ }^{\circ} \mathrm{C}$ with a maximum decomposition rate temperature of $256^{\circ} \mathrm{C}$ [57]. From $428{ }^{\circ} \mathrm{C}$ to $800{ }^{\circ} \mathrm{C}$, another mass of $10.4 \%$ was observed and associated to the dehydroxylation of the clay sheets and the progressive burnout of the residual carbonaceous materials [58] (Figure 9). The mass related to water molecules was reduced to 
$4.6 \%$ and was related mainly to physisorbed water molecules on the surface with a peak on the DTG curve at $64{ }^{\circ} \mathrm{C}[57,58]$. The mass related to coordinated water molecules to $\mathrm{Na}^{+}$cations vanished due to their exchange with C16TMA cations [59]. A similar feature was obtained for the OCs prepared from C16TMACl and C16TMAOH solutions (Figure 9). However, the area of the DTG peak related to the organic mass was lower, which indicated a lower organic content in the C16OHPG-2.40 clay. This fact was in good agreement with C.H, $\mathrm{N}$ analysis. The maximum temperature mass related to the loss of organic matter $\left(256^{\circ} \mathrm{C}\right)$ was higher for C16OHPG-2.40 compared to the other OCs at $244{ }^{\circ} \mathrm{C}$ and $236{ }^{\circ} \mathrm{C}$, which is presented in Figure 9. The variation in the temperature reflected the easiness to loss organic matter with higher contents due to the high expansion of the interlayer spacing and it was easy to remove them. However, with low content of organic matter, the basal spacing was not expanded sufficiently and the cations adopted a lateral monolayer arrangement, which made their removal between the clay sheets difficult. The decrease in the dehydration peak of DTG curves was related to the conversion of PG clay to the organophilic character.

A

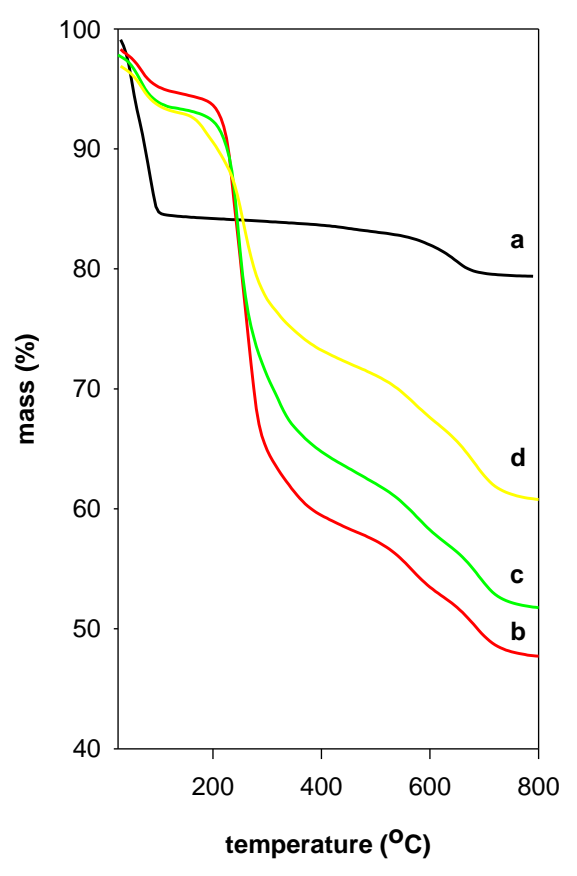

$A^{\prime}$

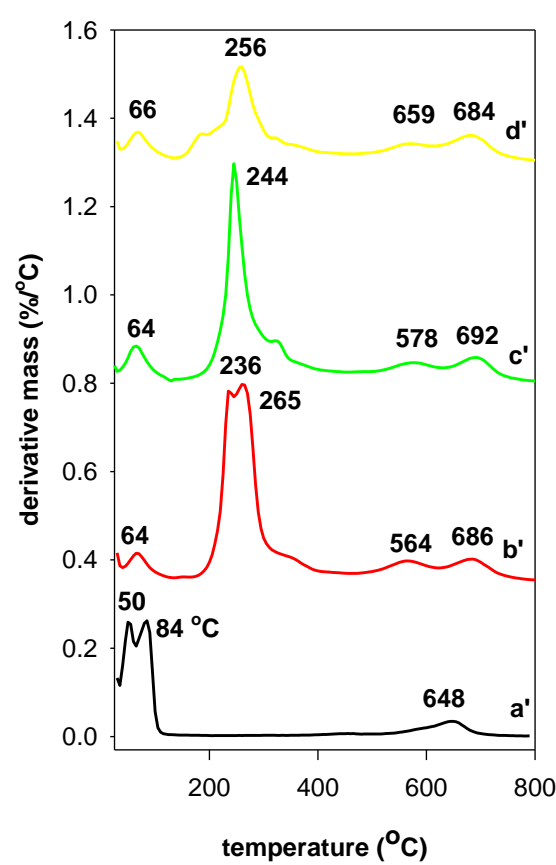

Figure 9. TGA (A) / DTG ( $\left.\mathbf{A}^{\prime}\right)$ features of $\left(\mathrm{a}, \mathrm{a}^{\prime}\right)$ PG modified with different C16TMA solutions at initial loading of $2.40 \mathrm{mmol} / \mathrm{g}$. (b, b') C16TMABr, (c, $\left.\mathrm{c}^{\prime}\right)$ C16TMACl and (d, d') C16TMAOH.

The different mass steps were accompanied with different events in the DTA curves. Figure S3 depicts the DTA features of PG clay and the OCs prepared from different C16TMA solutions. The loss of different types of water molecules from PG clay was associated to two endothermic peaks at $57^{\circ} \mathrm{C}$ and $90{ }^{\circ} \mathrm{C}$, respectively. However, in case of OCs, only one type of water molecule was lost at $65^{\circ} \mathrm{C}$. Additional exothermic peaks were observed at mainly $235^{\circ} \mathrm{C}$ and $373{ }^{\circ} \mathrm{C}$ with shoulders at $580{ }^{\circ} \mathrm{C}$ and $690^{\circ} \mathrm{C}$. These peaks were associated with the combustion of the organic surfactants and their residue carbon materials. The dehydroxylation of the OCs was difficult to detect when compared to the starting PG clay, which is associated with a broad endothermic peak at $650{ }^{\circ} \mathrm{C}$ [60].

From Table 6, the general trend related to water content could be noticed. The water content decreased in the OCs, which confirms that the $\mathrm{Na}^{+}$cations were fully exchanged and the OCs exhibited an organophilic character. The organic content depended on the used C16TMA solution. The experimental content was close to the theoretical values deduced from the $\mathrm{C}, \mathrm{H}, \mathrm{N}$ analysis. 
Table 6. Presents the water and the organic content in some selected OCs prepared from different surfactant solutions.

\begin{tabular}{cccc}
\hline Samples & Water Content (Mass\%) & Organic Content ${ }^{*}$ (Mass\%) & Residue at $\mathbf{9 0 0}{ }^{\circ} \mathbf{C}$ \\
\hline PG-clay & 15.54 & 0 & 79.49 \\
C16BrPG-2.40 & 3.51 & 36.13 & 47.52 \\
C16CIPG-2.40 & 4.26 & 35.43 & 53.56 \\
C16OHPG-2.40 & 3.85 & 18.79 & 63.56 \\
\hline
\end{tabular}

${ }^{*}$ Mass in the range of $180^{\circ} \mathrm{C}$ to $420^{\circ} \mathrm{C}$.

The C16TMABr salt exhibited one peak in the DTG feature at $240{ }^{\circ} \mathrm{C}$, which indicates that decomposition occurred cleanly in one single step with almost negligible residual mass (not shown). This value was lower to that reported for pure and recrystallized C16TMABr salt $\left(268{ }^{\circ} \mathrm{C}\right)$ [61]. The maximum decomposition temperature rate of the intercalated C16TMA cations occurred at higher temperatures when compared to the pure C16TMABr salt. This difference was related to the effect of the clay layers on the decomposition of the surfactants. However, in case of pure layered silicate materials that do not contain aluminum in their structures, the decomposition occurred at lower temperatures. The residues at $900{ }^{\circ} \mathrm{C}$ are $47.52 \%$ for C16BrPG-2.40, 53.56\% for C16ClPG-2.4, and $63.56 \%$ for C16OHPG-2.40. These were also distinctive, which confirms the structural modifications of the clays even though they retained their inorganic character.

For OCs prepared at different initial concentrations from C16TMABr solution, the TGA/DTG features are depicted in Figure 10, and the different mass percentages are summarized in Table 7. As the content of C16TMA cations increased in the synthesized materials, the mass related to water molecules decreased from $15.54 \%$ to $3.72 \%$ and only one type of water molecules was removed at a temperature of $60^{\circ} \mathrm{C}$ to $64^{\circ} \mathrm{C}$ (as indicated by the DTG peak) in addition to the area of this peak, which was also decreasing. At the same time, the area of the peak related to C16TMA cations was improved when the initial loading concentration rose. We noticed that the related maximum temperature peak was shifted to lower values. This shift indicated that, at higher organic content in the OCs, the C16TMA cations were easy to remove because of their particular arrangement in the interlayer space, which was not the case of lower C16TMA content. They exhibited different arrangements (with basal spacings of 2.14 and $2.51 \mathrm{~nm}$ ) and, per consequent, difficult to remove in good agreement with the reported data above.
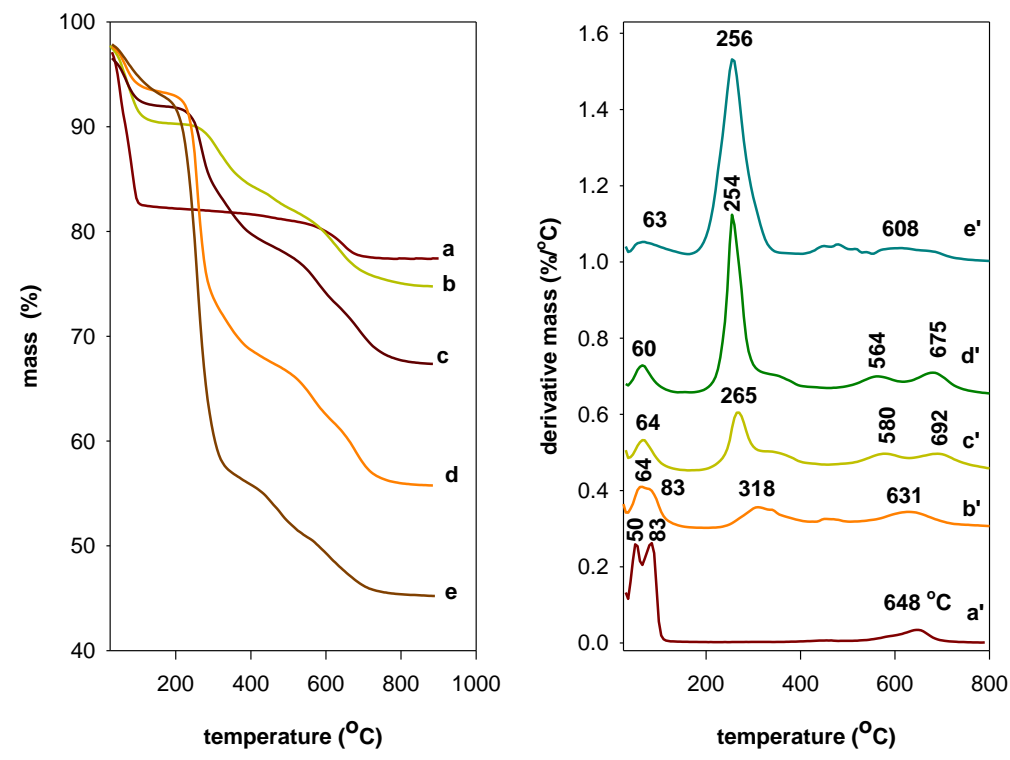

Figure 10. TGA (left)/DTG (right) curves of (a, a') PG clay modified with C16TMAbr solution at different concentrations (b, b') $0.40 \mathrm{mmol},\left(\mathrm{c}, \mathrm{c}^{\prime}\right) 0.80 \mathrm{mmol}$. (d, d') $1.65 \mathrm{mmol}$ and (e, e') $2.40 \mathrm{mmol}$. 
Table 7. Summarizes the mass related to water, surfactants molecules, and the residue from RT to $900{ }^{\circ} \mathrm{C}$ for samples prepared from C16TMABr solution.

\begin{tabular}{cccc}
\hline Samples & Water Content $\mathbf{( w t} \%)$ & Organic Content $\mathbf{( w \mathbf { t } \% )}$ & Residue at $\mathbf{9 0 0}{ }^{\circ} \mathbf{C}$ \\
\hline PG-clay & 15.54 & 0 & 79.49 \\
C16BrPG-0.40 & 7.49 & 6.36 & 77.14 \\
C16BrPG-0.80 & 4.71 & 12.97 & 67.26 \\
C16BrPG-1.65 & 4.22 & 26.17 & 57.94 \\
C16BrPG-2.40 & 3.72 & 34.98 & 49.08 \\
\hline
\end{tabular}

\subsection{Thermal Stability Study}

As mentioned in the experimental part, the in-situ XRD technique was performed to identify the appropriate temperature at which the OCs could be treated without losing their performance in the eosin removal process [25].

The Powder XRD pattern of C16TMABr salt consists of a multiple discrete peaks characteristic of a crystalline state and lamellar structure with a very sharp strong peak corresponding to a repeat ranging of $2.60 \mathrm{~nm}$ (Figure 11) [62]. The value of $2.6 \mathrm{~nm}$ was estimated from the position of the first five reflections.

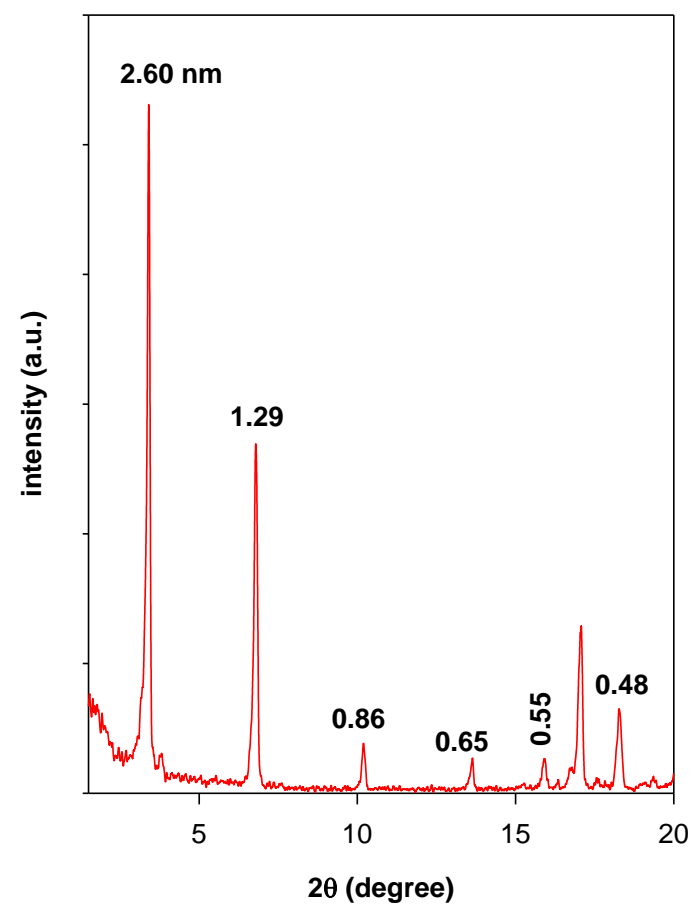

Figure 11. Powder XRD pattern of the starting C16TMABr salt.

After preheating at different temperatures, the powder XRD patterns are presented in Figure S5. The variation of the distance related to 001 reflection $\left(\mathrm{d}_{001}\right)$ is summarized in Figure 12. The layered structure of C16TMABr was maintained at temperatures of $215^{\circ} \mathrm{C}$ with a gradual increase of the $\mathrm{d}_{001}$ from $2.61 \mathrm{~nm}$ to $3.23 \mathrm{~nm}$. Then no reflection was detected due to the melting of the C16TMABr salt [25]. 


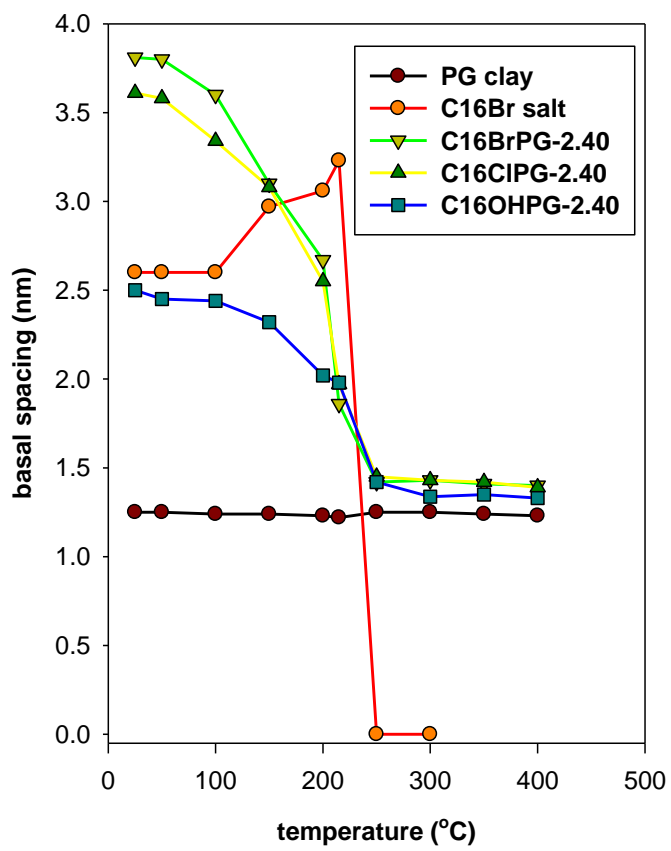

Figure 12. The variation of basal spacing $\left(\mathrm{d}_{001}\right)$ of different materials with preheated treatment temperatures.

The in-situ study of organo-clay (C16BrPG-2.40) indicated that the expanded form of the organo-clay was maintained at temperatures lower than $150{ }^{\circ} \mathrm{C}$.Then it collapsed to a value of $1.86 \mathrm{~nm}$ when treated at $215^{\circ} \mathrm{C}$. The basal spacing continued to shrink as the temperature increased due to the progress of the remaining carbon materials (Figure 12). Similar in situ data were obtained for the C16ClPG-2.40 and indicated that the expanded structure was maintained at temperatures lower than $200{ }^{\circ} \mathrm{C}$. The basal spacing values were in the range of 3.61 to $3.0 \mathrm{~nm}$. The chain of the carbon moiety was decomposed at $215^{\circ} \mathrm{C}$, which results in a decrease in the basal spacing of the organo-clay to $2.10 \mathrm{~nm}$. The intercalated C16TMA cations behave differently than the neat salt in the way that there was no increase of the basal spacing of the OCs in the range of 100 to $150{ }^{\circ} \mathrm{C}$, which was reported for the C16TMABr salt. However, when other types of silicate were used as a host matrix, the intercalated C16TMA cations behave in the same way than the C16TMABr salt $[25,63]$. This fact could be related to an intrinsic effect of the type of silicate layers and its properties.

In case of OC prepared from $\mathrm{C} 16 \mathrm{OH}$ solution (C16OHPG-2.40), the arrangement of the C16TMA cations was different than that of C16TMABr and C16TMACl solutions. The decrease of the basal spacing will occur at relatively higher temperatures, which is indicated by the TGA technique. The expanded organo-clay was maintained to temperatures up to $150{ }^{\circ} \mathrm{C}$ with a slight variation of the basal spacing. Then, it collapsed to $1.43 \mathrm{~nm}$ due to the combustion of the organic C16TMA cations, which was presented in Figure 12.

For all the materials, the basal spacing of treated materials $(1.43 \mathrm{~nm})$ at temperatures higher than $250{ }^{\circ} \mathrm{C}$ was higher than the basal spacing of the pristine PG treated at the same temperature $(1.24 \mathrm{~nm})$. This variation was related to the presence of the residual carbon materials between the clay sheets $[25,34]$. These data are in good accordance with the TGA data, which was presented in Table 4 .

\subsection{Removal Properties of Eosin Dye}

\subsubsection{Effect of the Initial Concentration}

The removal of eosin was investigated by varying the initial concentrations $\left(\mathrm{C}_{\mathrm{i}}\right)$ of the dye solution in the range of $25 \mathrm{mg} / \mathrm{L}$ to $1000 \mathrm{mg} / \mathrm{L}$ for the C16BrPG-2.40. The removal efficiency decreased from $100 \%$ to $85 \%$ since $C_{i}$ of eosin increased from $25 \mathrm{mg} / \mathrm{L}$ to $1000 \mathrm{mg} / \mathrm{L}$ (Figure S5). The reduction in eosin 
indicated that the available removal sites become lower at higher $C_{i}$ values since the mass of the OC was kept constant. However, the removal amount of the eosin increased from $2.5 \mathrm{mg} / \mathrm{g}$ to $76.5 \mathrm{mg} / \mathrm{g}$ since the initial eosin concentration increased from $25 \mathrm{mg} / \mathrm{L}$ to $1000 \mathrm{mg} / \mathrm{L}$ (as shown in Figure S5). At lower eosin initial concentration, the ratio between the numbers of eosin molecules to the number of available removal sites is low and the rate of diffusion of eosin molecules was slow. Hence, few dye molecules reach adsorption sites. However, a higher initial concentration provided a higher driving force for eosin molecules to approach removal sites more rapidly. Moreover, the number of collisions between dye molecules and adsorbent increases and improves the removal process $[64,65]$.

\subsubsection{Effect of C16TMA Contents}

Figure 13 shows the effect of the amounts of C16TMA contents on the removal capacities of eosin onto different OCs. As expected, the PG clay exhibited very low removal capacity due to the repulsion between the negative electrical charge of PG clay and eosin dye molecules [16]. Similar observations were noted for other silicate layered materials such as kenyaite and magadiite $[25,65]$.

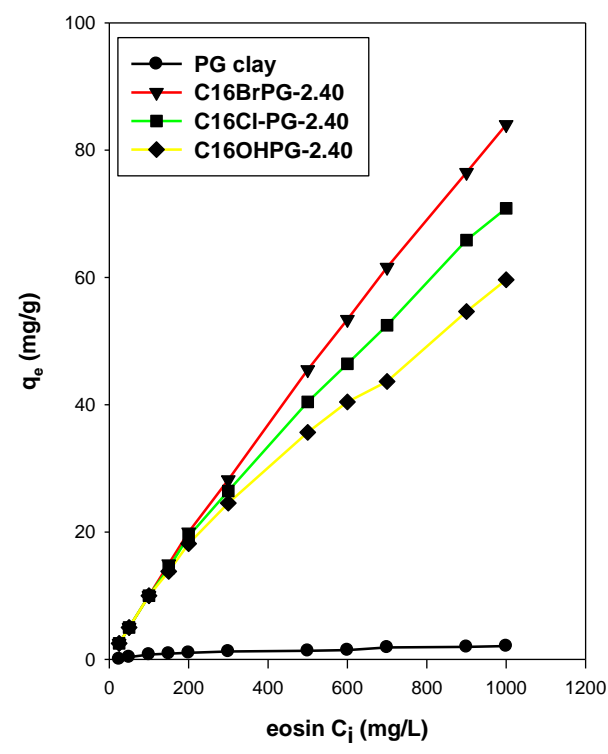

Figure 13. Removal of eosin at different initial concentrations by different OCs.

Figure 13 indicated that low removal capacities were obtained for low loading of the C16TMABr amount because of the remaining negative electrical charge on the PG clay surface [32]. As the C16TMA content increased, the removal amount was also improved due to the complete covering of the negative charge on PG clay by the surfactant, which means the electrical repulsion overcame [66-68]. Similar data were achieved using local clay mineral [32] and other silicate layered materials [25,63].

Figure 14 presents the removal efficacy of OCs prepared from the C16TMABr solution at different initial loading concentrations. At $C_{i}$ values lower than $200 \mathrm{mg} / \mathrm{L}$, the removed amount was independent of the amount of C16TMA cations in the OCs. At higher $C_{i}$ values greater than $200 \mathrm{mg} / \mathrm{L}$, the removed eosin was improved as the C16TMA contents increased in the OC materials. This part indicated that the modification of the PG clay with surfactants has enhanced the removal of an acidic dye. Similar data were obtained using different organo-silicates $[25,63]$. 


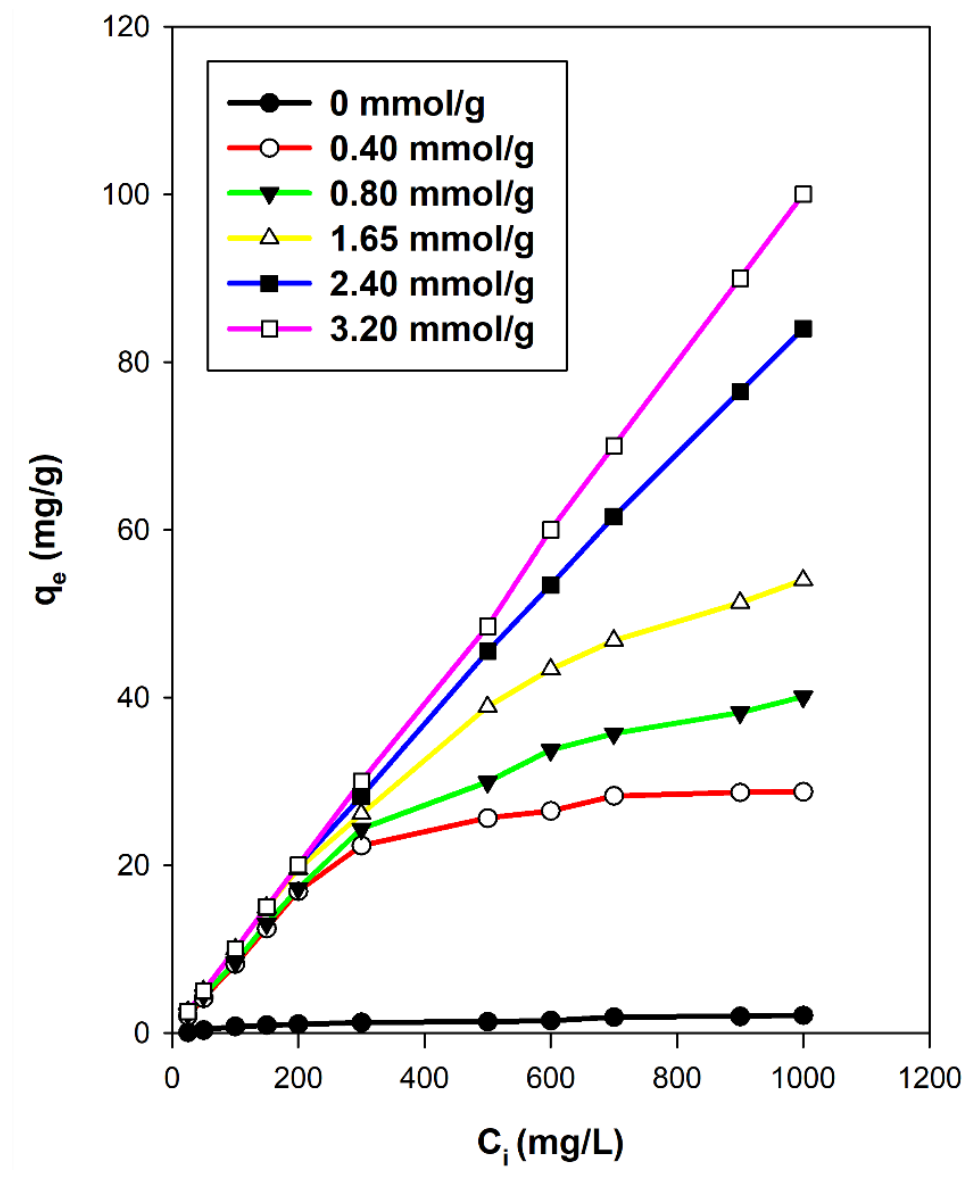

Figure 14. Removal of eosin using organo-clay prepared from C16TMABr solution using different initial loading concentrations.

The modification of the silicate surface by organic cations and mainly long ones such as C16TMAs rendered the PG clay an organophilic material [57]. The negatively charged surface of the silicate may adsorb the $\mathrm{C} 6 \mathrm{TMA}^{+}$cations through an ion exchange mechanism where a monolayer of cationic surfactants on the surface of the clay formed. The positively charged ends of the cationic surfactants were exchanged with the exchangeable interlayer cations of the PG clay $\left(\mathrm{Na}^{+}\right)$and the hydrophobic head of the cationic surfactants was arranged outward [57]. The C16 $\mathrm{TMA}^{+}$cations generated an organophilic phase partition in the interlayer spacing and the partition occurred through the interaction

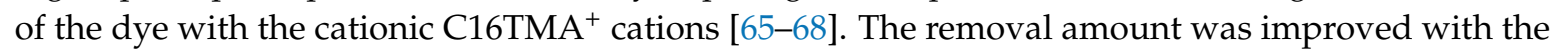
increase of eosin $C_{i}$ values independently of the used ogano-clay and the maximum value $(84 \mathrm{mg} / \mathrm{g})$ was obtained at $C_{i}$ of $1000 \mathrm{mg} / \mathrm{L}$ using C16BrPG-2.40.

It is observed that the organo-clays exhibited lower specific surface areas. However, the amount of removed eosin remained high, which suggested that the eosin molecules were removed into the interlamellar space. The PXRD patterns after the removal of dyes indicated a slight variation of the basal spacing and could indicate an anion exchange of $\mathrm{Br}$ anions with the removed eosin dyes [69].

\subsubsection{Effect of Temperature}

The temperature has important effects on the removal process [66]. Three different temperatures $\left(25^{\circ} \mathrm{C}, 35^{\circ} \mathrm{C}\right.$, and $\left.50^{\circ} \mathrm{C}\right)$ were studied. The temperature of $50^{\circ} \mathrm{C}$ was selected because no change in the OC structure occurred. It was observed that, as the experimental temperature increased, the removed amounts of eosin by the used OCs was improved and it varied from $84 \mathrm{mg} / \mathrm{g}$ to $110 \mathrm{mg} / \mathrm{g}$ (Figure S6). This suggests that the removal process is favored at higher temperatures. It is common that increasing 
the temperature may create a swelling influence inside the OCs in the eosin solution structure and additional eosin dye molecule penetrate the removal sites [70].

The distribution coefficient is an important parameter for estimating the affinity of OC towards eosin in aqueous solution. The quantity $K_{d}$ may be defined by Equation (1).

$$
K_{d}=\frac{C_{e}}{C_{a}}
$$

where $C_{e}$ is the equilibrium concentration $(\mathrm{mol} / \mathrm{L})$ and $C_{a}$ is the amount of dye adsorbed on the adsorbent at equilibrium (mol/L) [71]. The increase in temperatures was associated with an enhancement of the affinity of OC towards eosin, which is indicated by the increase of $K_{d}$ values (Table 8).

Table 8. Thermodynamic parameters of eosin removal using C16BrPG-2.40 organo-clay.

\begin{tabular}{cccc}
\hline \multirow{2}{*}{ Parameter } & \multicolumn{3}{c}{ Temperature } \\
\cline { 2 - 4 } & $\mathbf{2 9 8 ~ K}$ & $\mathbf{3 0 8 ~ K}$ & $\mathbf{3 2 3 ~ K}$ \\
\hline$\Delta G^{\circ}\left(\mathrm{kJ} \mathrm{mol}^{-1}\right)$ & -4.11 & -6.02 & -7.91 \\
$K_{d}$ & 5.25 & 10.49 & 19.00 \\
$\Delta S^{\circ}\left(\mathrm{kJ} \mathrm{mol}^{-1} \cdot \mathrm{K}\right)$ & & 0.153 & \\
$\Delta H^{\circ}\left(\mathrm{kJ} \mathrm{mol}^{-1}\right)$ & & 41.22 & \\
\hline
\end{tabular}

The thermodynamics parameters were estimated using Equations (1)-(3) [71] and are presented in Table 8.

$$
\Delta G^{\circ}=-R T \ln K_{d}
$$

The thermodynamics parameters were also estimated by using the Van't Hoff equation.

$$
\operatorname{Ln} K_{d}=\frac{\Delta S^{\circ}}{R}-\frac{\Delta H^{\circ}}{R T}
$$

where $R$ is the gas constant $\left(\mathrm{J} \mathrm{mol}^{-1} \mathrm{~K}^{-1}\right), \Delta G^{\circ}$ is the free energy $\left(\mathrm{kJ} \mathrm{mol}^{-1}\right), K_{d}$ is the distribution constant, $\mathrm{T}$ is the absolute temperature $(\mathrm{K}), \Delta H^{\circ}$ is the standard enthalpy $\left(\mathrm{kJ} \mathrm{mol}^{-1}\right)$, and $\Delta S^{\circ}$ is the standard entropy $\left(\mathrm{kJ} \mathrm{mol}^{-1} \mathrm{~K}\right) . \Delta S^{\circ}$ and $\Delta H^{\circ}$ values were achieved from the intercept and slope of plot $\ln K_{d}$ versus $1 / \mathrm{T}$.

These parameters provide details on the spontaneity, feasibility, and eosin-organo-clay interactions during the removal process. Figure S7 presents the Van't Hoff plot and exhibited alinearity. From Table 8 , the removal of eosin was an endothermic process with enthalpy $\left(\Delta H^{\circ}\right)$ being $41.22 \mathrm{~kJ} / \mathrm{mol}$. An increase in negativity of the Gibbs free energy $\left(\Delta G^{\circ}\right)$ with the temperature suggested improved spontaneity of the eosin-OC system at an elevated temperature. The entropy value of $\Delta S^{\circ}$ $(0.153 \mathrm{KJ} / \mathrm{mol})$ indicated that the eosin removal by OC leads to the randomness in the solid/liquid interface and suggested an increase of the disorder at the eosin-OC interface [72].

\subsubsection{Effect of Preheated Treatment of OCs}

For the convenience purposes, only two samples of OCs were selected in this part: C16BrPG-2.40 and C16OHPG-2.40. As mentioned above, these samples had different organic contents.

Figure 15 presents the evolution of the removed amount of eosin as it functions in the preheated temperatures of the C16BrPG-2.40 in the $C_{i}$ range of 25 to $1000 \mathrm{mg} / \mathrm{L}$. At $\mathrm{C}_{\mathrm{i}}$ values less than $200 \mathrm{mg} / \mathrm{L}$, the removed amount was independent of the preheated temperatures less than $150{ }^{\circ} \mathrm{C}$. However, it was reduced when C16BrPG-2.40 preheated at temperatures higher than $200{ }^{\circ} \mathrm{C}$ and $\mathrm{C}_{\mathrm{i}}$ values higher than 200 ppm due to the beginning of the decomposition of C16TMA cations, which was deduced from TGA and the in situ studies. Preheat treatment at temperatures higher than $230{ }^{\circ} \mathrm{C}$ resulted in a reduction of removed eosin amounts due to the complete breakdown of the intercalated C16TMA 
cations (as indicated by the in situ XRD studies). Per consequent, a destruction of the active sites responsible for the removal of eosin occurred. The clear effect of preheat treatment was observed at higher $\mathrm{C}_{\mathrm{i}}$ value of 300 to $1000 \mathrm{mg} / \mathrm{L}$.

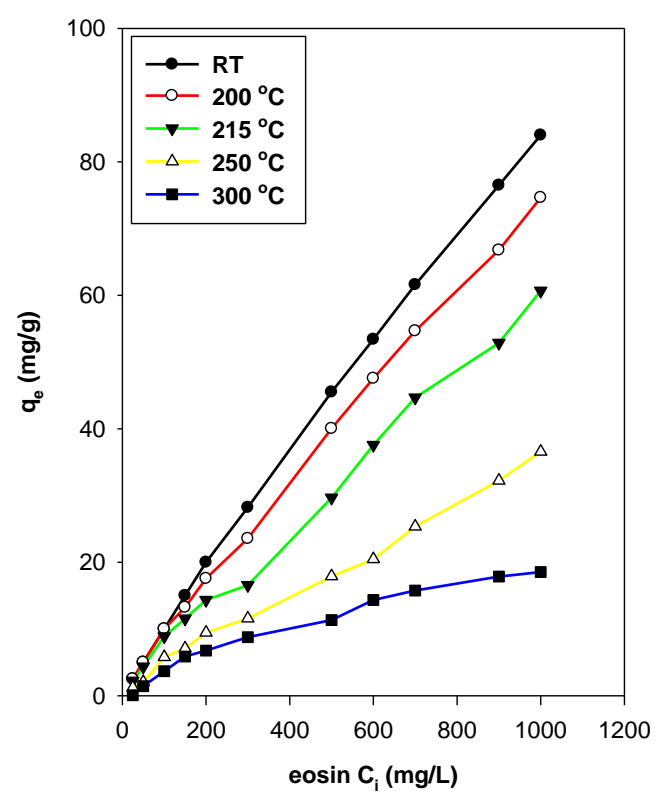

Figure 15. Removal capacity of C16BrPG-2.40 preheated at different temperatures.

The C16OHPG-2.40 exhibited similar behavior, which indicated that the removal properties were maintained at heating temperatures higher than $150{ }^{\circ} \mathrm{C}$ for lower $\mathrm{C}_{\mathrm{i}}$ values than $200 \mathrm{mg} / \mathrm{L}$ (Figure S8). However, less extension is compared to C16BrPG-2.40 due to the lower contents of C16TMA in the $\mathrm{C} 16 \mathrm{OHPG}-2.40$. The removed amount of eosin was reduced at preheated temperatures higher than $200{ }^{\circ} \mathrm{C}$ due to the decomposition of C16TMA cations and due to the loss of the removal sites. The decrease was also observed for higher concentrations of $1000 \mathrm{mg} / \mathrm{L}$.

Similar data were reported for similar silicate layers such as kenyaite and magadiite $[25,63]$. Nevertheless, the preheated treatment may help find the optimal temperature at which the modified OCs could be used. The preheated temperatures were reported to affect the adsorption properties of nitrobenzene too [73]. Compared to PG clay, the preheated OCs at temperatures higher than $250{ }^{\circ} \mathrm{C}$ still exhibited minor removal properties due to the remaining sites.

\subsection{Maximum Removal Amount}

The Langmuir equation was used to estimate the maximum removed amount $\left(q_{\mathrm{m}}\right)$. This equation was based on the assumption that a monolayer is adsorbed and covers all the available surface of the adsorbent [74]. The linearized Langmuir isotherm allows for the calculation of the adsorption capacity $\left(q_{\max }\right)$ and the Langmuir constant $\left(K_{L}\right)$ that are equated by Equation (4).

$$
\frac{C_{e}}{q_{e}}=\frac{1}{q_{\max } \cdot K_{L}}+\frac{C_{e}}{q_{\max }}
$$

where $C_{e}$ and $q_{e}$ are the concentration at equilibrium $(\mathrm{mg} / \mathrm{g})$ and the amount adsorbed at equilibrium (mg/g), respectively. These constants can be estimated from the intercept and slope of the linear plot of the experimental data of $C_{e} / q_{e}$ versus $C_{e}$.

As mentioned above, the modification of PG clay with C16TMA cations has improved its removal capacities (Table 9). The maximum value of $90.90 \mathrm{mg}$ of eosin $/ \mathrm{g}$ of OC was achieved for the C16BrPG-2.40 as starting material. However, the lowest value of $60.60 \mathrm{mg} / \mathrm{g}$ was attained using C16OHPG-2.40. The removal efficiency was dependent on the preheated treatment. It was 
maintained at temperatures below $210{ }^{\circ} \mathrm{C}$. Then it was decreased significantly. This fact was related to the destruction of the intercalated C16TMA cations and, thus, there was no availability of removal sites in this process (Table 9). The $K_{L}$ (parameter of the Langmuir model) is a measure of the affinity between the esoin dye and the organo-clays. In other words, it expresses the binding constant of eosin and the organ-clay. Since the binding is based on the electrostatic interaction, the $K_{L}$ value increased when the removed amount was improved (Table 9). Similar trends were obtained for a different organo-silicates $[25,63]$.

Compared to local clay mineral and other silicate materials, the OC prepared from PG clay exhibited higher removal efficiency due to the difference in organic contents (Table 10). These data indicated that the OCs derived from PG clay mineral could be considered as a potential candidate for dyes removal.

Table 9. Langmuir parameters of the eosin removal by different OCs.

\begin{tabular}{|c|c|c|c|}
\hline Samples & $q_{\max }\left(\mathrm{mg} \mathrm{g}^{-1}\right)$ & $K_{L}\left(\mathrm{~L} \mathrm{~g}^{-1}\right)$ & $\mathbf{R}^{2}$ \\
\hline PG clay & 3.45 & 0.00054 & 0.9675 \\
\hline C16BrPG-2.40 & 90.90 & 0.0263 & 0.9934 \\
\hline C16ClPG-2.40 & 74.07 & 0.0154 & 0.9921 \\
\hline C16OHPG-2.40 & 60.60 & 0.0117 & 0.9886 \\
\hline C16BrPG-0.40 & 30.76 & 0.0223 & 0.9974 \\
\hline C16BrPG-0.80 & 46.20 & 0.0242 & 0.9873 \\
\hline C16BrPG-1.65 & 54.64 & 0.0653 & 0.9885 \\
\hline C16BrPG-3.20 & 94.20 & 0.1234 & 0.9921 \\
\hline C16BrPG-2.40 (100) * & 75.11 & 0.0096 & 0.9914 \\
\hline C16BrPG-2.40 (150) * & 75.11 & 0.0096 & 0.9934 \\
\hline C16BrPG-2.40 (200) * & 64.47 & 0.0063 & 0.9827 \\
\hline C16BrPG-2.40 (215) * & 53.76 & 0.0039 & 0.9854 \\
\hline C16BrPG-2.40 (250) * & 38.09 & 0.0014 & 0.9875 \\
\hline
\end{tabular}

Table 10. Removal capacities of various adsorbents for eosin dye.

\begin{tabular}{ccc}
\hline Samples & $\boldsymbol{q}_{\max }(\mathbf{m g} / \mathbf{g})$ & References \\
\hline Organo-PG clays & 75.11 to 90.90 & [This work] \\
Organo-magadiites & 69.54 & {$[63]$} \\
Organo-local clays & 48.66 & {$[32]$} \\
Organo-kenyaites & 48.01 & {$[25]$} \\
Raw fly ash & 43.48 & {$[75]$} \\
Alumina nanoparticles & 47.78 & {$[76]$} \\
\hline
\end{tabular}

\subsection{Regeneration Cycles}

The removal of eosin by OCs concentrates the dye molecules by transferring them into other phases and these concentrated dye molecules cause another environmental disposal problem. A good removal agent will depend not only on its removal capacity but how well it can be regenerated and repeatedly used.

Different methods of regeneration were proposed in the literature including thermal treatments, Fenton oxidation, wet air oxidation, biological, ultrasound, electrochemical methods, and microwaves, etc. [77]. In this study, we used an environmentally-friendly method in the sense that it does not use a lot of chemicals and the solution could be used repeatedly many times without losing its efficiency [25,63].

The regeneration of C16BrPG-2.40 was investigated using two eosin $\mathrm{C}_{\mathrm{i}}$ values of $50 \mathrm{mg} / \mathrm{L}$ and $500 \mathrm{mg} / \mathrm{L}$. At lower $\mathrm{C}_{\mathrm{i}}$ value of $50 \mathrm{mg} / \mathrm{L}$, the removal efficiency was maintained till six cycles of re-use with slight variation of the removal percentage from $95 \%$ to $90 \%$. Then it dropped to $7 \%$. However, using high $C_{i}$ value of $500 \mathrm{mg} / \mathrm{L}$, the removal percentage of C16BrPG-2.40 was maintained after 
4 removal/regeneration cycles and it varied from $93 \%$ to $80 \%$. Then, it dropped to $45 \%$ after 6 cycles (Figure 16A). In case of C16OHPG-2.40 and for $\mathrm{C}_{\mathrm{i}}$ of $500 \mathrm{mg} / \mathrm{L}$, its efficiency was maintained for 3 cycles of regeneration and it varied from $71 \%$ to $63 \%$. A significant drop was observed after the fourth cycle to $55 \%$ and it continuously decreased to $40 \%$ after the sixth cycle. For low $\mathrm{C}_{\mathrm{i}}$ of $50 \mathrm{mg} / \mathrm{L}$, the efficiency was maintained to the sixth cycle and varied from $100 \%$ to $90 \%$. Then it dropped to $70 \%$ (Figure 16B). The decrease in the removal efficiency could indicate that some eosin anions were strongly attached to the removal sites, which makes it difficult to oxidize them by the used aqueous solution of oxone and $\mathrm{Co}^{2+}$ cations for the regeneration process [25,33].

A

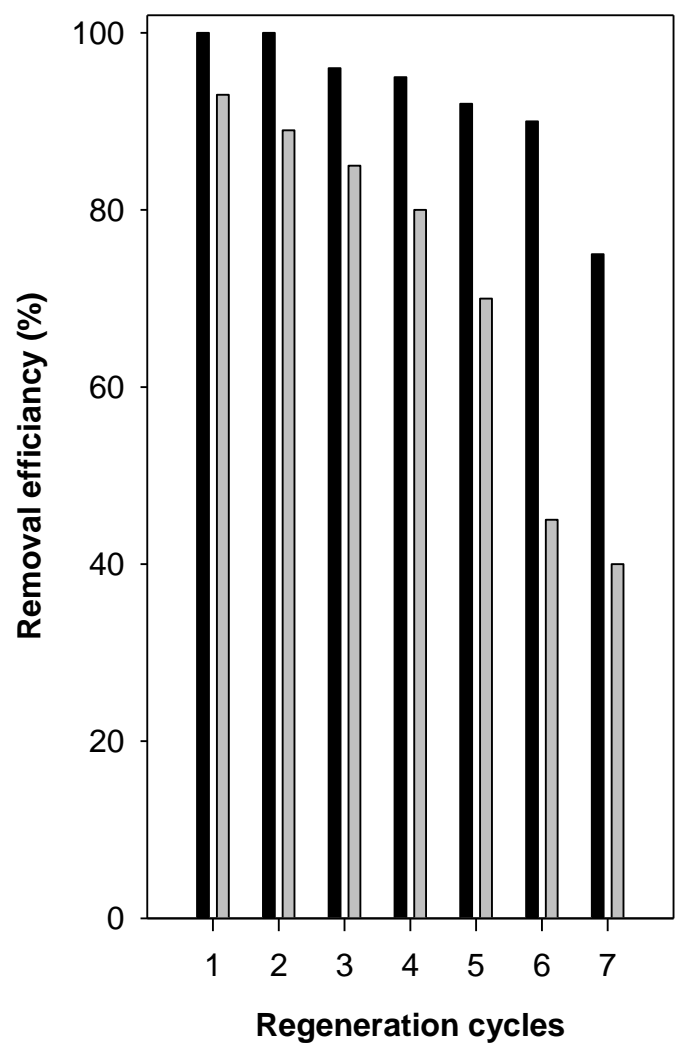

B

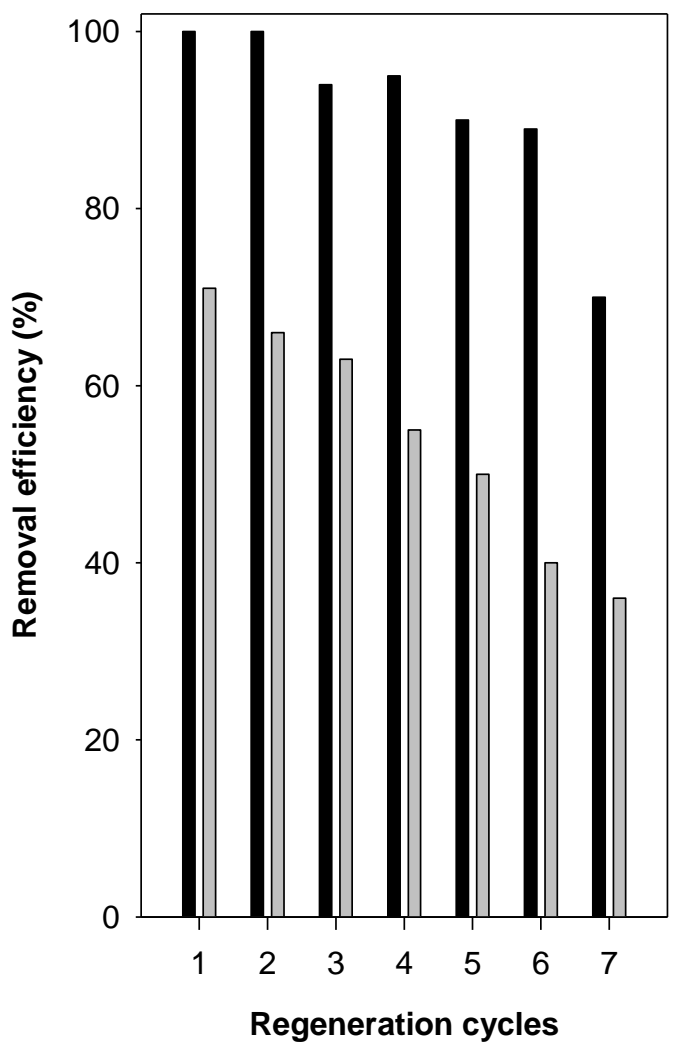

Figure 16. Regeneration efficiency of (A) C16BrPG-2.40 (B) C16OHPG-2.40 using $C_{i}$ of 50 mg/L (dark bar) and $200 \mathrm{mg} / \mathrm{L}$ (grey bar).

\section{Conclusions}

The removal of anionic dye molecules "eosin" is weak at the PG clay mineral surface due to the negative charge of its surface. However, the modification with C16TMA cations has improved its removal efficiency and capacity. A maximum of $90.90 \mathrm{mg} / \mathrm{g}$ was achieved. The removed amount was controlled by the initial concentration, the operating temperature, and the preheat treatment of the OCs prior to their use.

The intercalated amount of C16TMA cations played an important role in the eosin removal and it could be tuned by varying the initial loading concentrations or choosing the right counter-ion in the starting solution. The C16TMABr solution has led to higher uptake of C16TMA cations $(1.60 \mathrm{mmol} / \mathrm{g})$, which is superior to the CEC value $(1.45 \mathrm{meq} / \mathrm{g})$. Apart from the C16TMAOH solution, the up take amount of organic surfactants was lower than the CEC value. The arrangement of C16TMA intercalated cations depended on the up take amount. Higher basal spacing of $3.82 \mathrm{~nm}$ was achieved for an uptake amount of $1.60 \mathrm{mmol} / \mathrm{g}$, which is associated with a bilayer arrangement with a tilt angle of $32^{\circ}$ on the clay sheets. ${ }^{13} \mathrm{C}$ CP NMR indicated that the intercalated C16TMA cations exhibited mainly 
all trans conformation in addition to gauche conformation. The modified OCs exhibited an organophilic character deduced from the TGA data. The preheat treatment of two selected OCs affected their eosin removal properties at temperatures higher than $215^{\circ} \mathrm{C}$ where the C16TMA cations were decomposed and accompanied by the loss in eosin removal efficiency. The regeneration process indicated that the removal property was maintained up to 6 cycles depending on the eosin $C_{i}$ values. These data could indicate that the prepared OCs will be considered as a potential candidate to act as a removal agent for eosin dye molecules with a maximum of $90 \mathrm{mg} / \mathrm{g}$.

Supplementary Materials: The following are available online. Figure S1: Variation of basal distance $\left(\mathrm{d}_{001}\right)$ with the initial loading concentrations of C16TMAOH solution, Figure S2: Deconvolution of 13C CP MAS peaks in the range of $25 \mathrm{ppm}$ to $45 \mathrm{ppm}$ for C16TMABr salt and the OC materials, Figure S3: DTA curves of (a) PG clay and organo-clays prepared from different solutions (b) C16TMABr, (c) C16TMACl, and (d) C16TMAOH solutions, Figure S4: PXRD patterns of C16TMABr salt preheated at different temperatures $\left({ }^{\circ} \mathrm{C}\right)$, Figure S5: Evolution of removed amount (mg/g) and removal percentage (\%) using C16BrPG-2.40 organo-clay, Figure S6: Eosin removal properties of C16BrPG-2.40 organo-clay performed at different temperatures, Figure S7: The Van't Hoff plot of eosin removal by C16BrPG-2.40 organo-clay at different temperatures, Figure S8: Removal capacity of C16OHPG-2.40 preheated at different temperatures and using two $\mathrm{C}_{\mathrm{i}}$ values $200 \mathrm{mg} / \mathrm{L}$ (black) and $1000 \mathrm{mg} / \mathrm{L}$ (red).

Author Contributions: Conceptualization, F.K. and Y.L.; Data curation (F.K., Y.L., M.A., H.O.H. and R.A.-F.; Formal analysis, F.K., S.R. and H.O.H.; Funding acquisition, F.K. and Y.L.; Investigation, F.K.; Y.L., M.A., H.O.H. and R.A.-F.; Methodology, F.K., R.A.-F. and Y.L.; Project administration, F.K.; Resources; F.K., Y.L., R.A.-F., M.A., S.R. and S.M.I.; Supervision; F.K. and M.A.; Validation, F.K., R.A.-F. and M.A.; Visualization, F.K., H.O.H.,M.A., S.R. and S.M.I.; Writing-Original Draft Preparation, F.K., H.O.H. and S.M.I.; Project Administration, F.K. and Y.L.

Funding: This research received no external funding.

Acknowledgments: The authors would like to thank Guilherme L Dotto (from the Federal University of Santa Maria, Brazil) for his help to get the optimized three-dimensional structural formula of the eosin Y using MarvinSketch software, version 14.9.22.0.

Conflicts of Interest: The authors declare no conflict of interest.

\section{References}

1. Nazir, M.S.; Mohamad Kassim, M.H.; Mohapatra, L.; Gilani, M.A.; Raza, M.R.; Majeed, K. Characteristic Properties of Nanoclays and Characterization of Nanoparticulates and Nanocomposites. In Nanoclay Reinforced Polymer Composites; Jawaid, M., Qaiss, A., Bouhfid, R., Eds.; Engineering Materials; Springer: Singapore, 2016; pp. 33-35.

2. Uddin, F. Clays, nanoclays, and montmorillonite minerals. Metall. Mater. Trans. A 2008, 39, $2804-2814$. [CrossRef]

3. CalabiFloody, M.; Theng, B.K.G.; Reyes, P.; Mora, M.L. Natural nanoclays: Applications and future trends a Chilean perspective. Clay Min. 2009, 44, 161-176. [CrossRef]

4. Beall, G.W. The use of OCs in water treatment. Appl. Clay Sci. 2003, 24, 11-20. [CrossRef]

5. Lee, S.M.; Tiwari, D. Organo and inorgan0-organo-modified clays in the remediation of aqueous solutions: An overview. Appl. Clay Sci. 2012, 59-60, 84-102. [CrossRef]

6. Pandey, S.; Ramontja, J. Natural bentonite clay and its composites for dye removal: Current state and future potential. Amer. J. Chem. Appl. 2016, 3, 8-19.

7. Paiva, L.B.; Morales, A.R.; Valenzuela Díaz, F.R. Organoclays: Properties, preparation and applications. Appl. Clay Sci. 2008, 42, 8-24. [CrossRef]

8. Young, D.A.; Smith, D.E. Simulations of clay mineral swelling and hydration: Dependence upon interlayer ion size and charge. J. Phys. Chem. B 2000, 104, 9163-9170. [CrossRef]

9. Nigam, C.; Setua, D.K.; Mathu, G.N.; Kar, K.K.J. Epoxy-montmorillonite clay nanocomposites: Synthesis and characterization. Appl. Polym. Sci. 2004, 93, 2201-2210. [CrossRef]

10. Bezrodna, T.; Puchkovska, G.; Styopkin, V.; Baran, J. Structure of cetyltrimethylammonium bromide films obtained by evaporation-induced precipitation method. Thin Solid Films 2009, 517, 1759-1764. [CrossRef]

11. Groisman, L.; Rav-Acha, C.; Gerstl, Z.; Mingelrin, U. Sorption and detoxification of toxic compounds by a bifunctional organoclays. J. Environ. Qual. 2004, 33, 1930-1936. [CrossRef] [PubMed] 
12. Xu, S.; Boyd, A. Alternative Model for Cationic Surfactant Adsorption by Layer Silicates. Environ. Sci. Technol. 1995, 29, 3022-3028. [CrossRef] [PubMed]

13. Komadel, P.; Madejova, J. Handbook of Clay Science; Elsevier: Amesterdam, The Netherlands, 2006.

14. Heinz, H.; Vaia, R.A.; Krishnamoorti, R.; Farmer, B.L. Self-assembly of alkylammonium chains on montmorillonite: Effect of chain length, head group structure, and cation exchange capacity. Chem. Mater. 2007, 19, 59-68. [CrossRef]

15. Liu, R.; Frost, R.L.; Martens, W.N.; Yuan, Y. Synthesis, characterization of mono, di and tri alkyl surfactant intercalated Wyoming montmorillonite for the removal of phenol from aqueous systems. J. Colloid Interface Sci. 2008, 32, 287-294. [CrossRef] [PubMed]

16. Baskaralingam, P.; Pulikesi, M.; Elango, D.; Ramamurthi, V.; Sivanesan, S. Adsorption of acid dye onto organobentonite. J. Hazard. Mater. 2006, 128, 138-144. [CrossRef] [PubMed]

17. Gonzaga, A.C.; Sousa, B.V.; Santana, L.N.L.; Neves, G.A.; Rodrigues, M.G.F. Study of different methods in the preparation of organoclays from the bentonite with application in the petroleum industry. Braz. J. Pet. Gas. 2007, 1, 16-25.

18. Cifuentes, A.; Bernat, J.L.; Diez-Masa, J.C. Determination of critical micelle concentration values using capillary electrophoresis instrumentation. Anal. Chem. 1997, 69, 4271-4274. [CrossRef]

19. Magid, L.J.; Han, Z.; Warr, G.C.; Cassidy, M.A.; Butler, P.D.; Hamilton, W.A. Effect of counterion competition on micellar growth horizons for cetyltrimethylammonium micellar surfaces: electrostatics and specific binding. J. Phys. Chem. B 1997, 101, 7919-7927. [CrossRef]

20. Rashidi-Alavijeh, M.; Javadian, S.; Gharibi, H.; Moradi, M.; Tehrani-Bagha, A.; Shahir, A.A. Intermolecular interactions between a dye and cationic surfactants: Effects of alkyl chain, head group, and counterion. Colloid Surf. A 2011, 380, 119-127. [CrossRef]

21. Kooli, F. Exfoliation properties of acid-activated montmorillonites and their resulting organoclays. Langmuir 2009, 25, 724-730. [CrossRef] [PubMed]

22. Kooli, F.; Khimyak, Y.Z.; Alshahateet, S.F.; Chen, F. Effect of the acid activation levels of montmorillonite clay on the cetyltrimethylammonium cations adsorption. Langmuir 2005, 21, 8717-8723. [CrossRef] [PubMed]

23. Kooli, F; Yan, L. Thermal stable cetyl trimethylammonium-magadiites: Influence of the surfactant solution type. J. Phys. Chem. C 2009, 113, 1947-1952. [CrossRef]

24. Crini, G. Non-conventional low-cost adsorbents for dye removal: A review. Bioresour. Technol. 2006, 97, 1061-1085. [CrossRef] [PubMed]

25. Kooli, F.; Liu, Y.; Hbaieb, K.; Al-Faze, R. Characterization of organo-kenyaites: Thermal stability and their effects on eosin removal characteristics. Clay Miner. 2018, 53, 91-104. [CrossRef]

26. Bhatnagar, A.; Sillanpaa, M. Utilization of agro-industrial and municipal waste materials as potential adsorbents for water treatment-A review. Chem. Eng. J. 2010, 157, 277-296. [CrossRef]

27. Su, Y.; Jiao, Y.; Dou, C.; Han, R. Biosorption of methyl orange from aqueous solutions using cationic surfactant-modified wheat straw in batch mode. Desalin. Water Treat. 2014, 52, 6145-6155. [CrossRef]

28. Hunger, K. Industrial Dyes: Chemsitry, Properties, Applications; Wiley-VCH: Weinhiem, Germany, 2003.

29. Sabnis, R.W. Handbook of Biological Dyes and Stains: Synthesis and Industrial Applications; John Wiley and Sons: Hoboken, NJ, USA, 2010; p. 173.

30. Mittal, A.; Jhare, D.; Mittal, J. Adsorption of hazardous dye eosin yellow from aqueous solution onto waste material de-oiled soya: Isotherm, kinetics and bulk removal. J. Mol. Liq. 2013, 179, 133-140. [CrossRef]

31. Kooli, F.; Liu, Y.; Alshahateet, S.F.; Messali, M.; Bergaya, F. Reaction of acid activated montmorillonites with hexadecyl trimethylammonium bromide solution. Appl. Clay Sci. 2009, 43, 357-363. [CrossRef]

32. Al-Faze, R.; Kooli, F. Eosin removal properties of organo-local clay from aqueous solution. Orient. J. Chem. 2014, 30, 675-680. [CrossRef]

33. Kooli, F.; Liu, Y.; Al-Faze, R.; Al-Suhaimi, A. Effect of acid activation of Saudi local clay mineral on removal properties of basic blue 41 from an aqueous solution. Appl. Clay Sci. 2015, 116-117, 23-30. [CrossRef]

34. Kooli, F. Organo-bentonites with improved cetyltrimethylammonium contents. Clay Miner. 2014, 49, 683-692. [CrossRef]

35. He, H.; Ma, Y.; Zhu, J.; Yuan, P.; Qing, Y. Organoclays prepared from montmorillonites with different cation exchange capacity and surfactant configuration. Appl. Clay Sci. 2010, 48, 67-72. [CrossRef]

36. Slade, P.G.; Gates, W.P. The swelling of HDTMA smectites as influenced by their preparation and layer charges. Appl. Clay Sci. 2004, 25, 93-101. [CrossRef] 
37. Slade, P.G.; Gates, W.P. The ordering of HDTMA in the interlayers of vermiculite and the influence of solvents. Clays Clay Miner. 2004, 52, 204-210. [CrossRef]

38. Ferrage, E.; Sakharov, B.A.; Michot, L.J.; Delville, A.; Bauer, A.; Lanson, B.; Grangeon, S.; Frapper, G.; Jimenez-Ruiz, M.; Cuello, G.J. Hydration properties and interlayer organization of water and ions in synthetic Na-smectite with tetrahedral layer charge. part 2. toward a precise coupling between molecular simulations and diffraction data. J. Phys. Chem. C 2011, 115, 1867-1881. [CrossRef]

39. Huang, W.L.; Bassett, W.A.; Wu, T.C. Dehydration and hydration of montmorillonite at elevated temperatures and pressures monitored using synchrotron radiation. Amer. Mineral. 1994, 79, 683-691.

40. Kooli, F. Effect of C16TMA contents on the thermal stability of organo-bentonites: In situ X-ray diffraction analysis. Thermochim. Acta 2013, 551, 7-13. [CrossRef]

41. He, H.; Duchet, J.; Galy, J.; Gerard, J.F. Influence of cationic surfactant removal on the thermal stability of organoclays. J. Colloid Interface Sci. 2006, 295, 202-208. [CrossRef] [PubMed]

42. Lepoitevin, M.; Balme, S.; Jaber, M.; Guégan, R.; Janot, J.M.; Dejardin, P.; Henn, F. BSA and lysozyme adsorption on montmorillonite: Influence of the interlayercation. Appl. Clay Sci. 2014, 95, 396-402. [CrossRef]

43. Zhu, R.; Zhu, L.; Zhu, J.; Xu, L. Structure of cetyltrimethylammonium intercalated hydrobiotite. Appl. Clay Sci. 2008, 42, 224-231. [CrossRef]

44. Lan, T.; Kaviratna, P.D.; Pinnavaia, T.J. Mechanism of clay tactoid exfoliation in epoxy-clay nanocomposites. Chem. Mater. 1995, 7, 2144-2150. [CrossRef]

45. Wang, L.Q.; Liu, J.; Exarhos, G.J.; Flanigan, K.Y.; Bordia, R. Conformation Heterogeneity and Mobility of Surfactant Molecules in Intercalated Clay Minerals Studied by Solid-State NMR. J. Phys. Chem. B 2000, 104, 2810-2816. [CrossRef]

46. Gerstmans, A.; Urbanczyk, L.; Jérôme, R.; Robert, J.L.; Grandjean, J. XRD and NMR characterization of synthetic hectorites and the corresponding surfactant-exchanged clays. Clays Clay Miner. 2008, 43, 205-212. [CrossRef]

47. Earl, W.L.; VanderHart, D.L. Observations in solid polyethylenes by Carbon-13 Nuclear Magnetic Resonance with Magic Angle Sample Spinning. Macromolecules 1979, 12, 762-767. [CrossRef]

48. Tonelli, A.E.; Schilling, F.C. Carbon-13 NMR chemical shifts and the microstructure of polymers. Acc. Chem. Res. 1981, 14, 233-238. [CrossRef]

49. Mungse, H.P.; Singh, R.; Sugimura, H.; Kumar, N.; Khatri, O.P. Molecular pillar supported graphene oxide framework: Conformational heterogeneity and tunable d-spacing. Phys. Chem. Chem. Phys. 2015, 17, 20822-20829. [CrossRef] [PubMed]

50. He, H.; Frost, R.L.; Deng, F.; Zhu, J.X.; Wen, X.Y.; Yuan, P. Conformation of Surfactant Molecules in the Interlayer of Montmorillonite Studied by ${ }^{13}$ C MAS NMR. Clays Clay Miner. 2004, 52, 350-356. [CrossRef]

51. Naik, V.V.; Vasudevan, S. Effect of Alkyl chain arrangement on conformation and dynamics in a surfactant intercalated layered double hydroxide: Spectroscopic measurements and MD simulations. J. Phys. Chem. C 2011, 115, 8221-8232. [CrossRef]

52. Simonutti, R.; Comotti, A.; Bracco, S.; Sozzani, P. Surfactant organization in MCM-41 mesoporous materials as studied by ${ }^{13} \mathrm{C}$ and ${ }^{29} \mathrm{Si}$ Solid-State NMR. Mater. Chem. 2001, 13, 771-777. [CrossRef]

53. Zhao, Q.; Choo, H.; Bhatt, A.; Burns, S.E.; Bate, B. Review of the fundamental geochemical and physical behaviors oforganoclays in barrier applications. Appl. Clay Sci. 2017, 142, 2-20. [CrossRef]

54. He, H.P.; Frost, R.L.; Bostrom, T.; Yuan, P.; Duong, L.; Yang, D.; Yunfel, X.F.; Kloprogge, J.T. Changes in the morphology of organoclays with HDTMA (+) surfactant loading. Appl. Clay Sci. 2006, 31, 262-271. [CrossRef]

55. Bate, B.; Choo, H.; Burns, S. Dynamic properties of fine-grained soils engineered with a controlled organic phase. Soil Dyn. Earthq. Eng. 2013, 53, 176-186. [CrossRef]

56. Burns, S.E.; Bartelt-Hunt, S.L.; Smith, J.A.; Redding, A.Z. Coupled mechanical and chemical behavior of bentonite engineered with a controlled organic phase. J. Geotech. Geoenviron. Eng. 2006, 132, 1404-1412. [CrossRef]

57. Kooli, F.; Yan, L.; Tan, S.X.; Zheng, J. Organoclays from alkaline-treated acid-activated clays: Properties and thermal stability. J. Therm. Anal. Calorim. 2014, 115, 1465-1475. [CrossRef]

58. Wolters, F.; Emmerich, K. Thermal reactions of smectites-Relation of dehydroxylation temperature to octahedral structure. Thermochim. Acta 2007, 462, 80-88. [CrossRef] 
59. Xie, W.; Gao, Z.; Liu, K.; Pan, W.P.; Vaia, R.; Hunter, D.; Singh, A. Thermal characterization of organically modified montmorillonite. Thermochim. Acta 2001,367-368, 339-350. [CrossRef]

60. Onal, M.; Sarikaya, Y. Thermal analysis of some organoclays. J. Thermal. Anal. Calirom. 2008, 91, $261-265$. [CrossRef]

61. Zhang, T.; Xu, G.; Puckette, J.; Blum, F.D. Effect of Silica on the Structure of Cetyltrimethylammonium Bromide. J. Phys. Chem. C 2012, 116, 11626-11634. [CrossRef]

62. Tomašić, V.; Popović, S.; Filipović-Vinceković, N. Solid State Transitions of Asymmetric Cationic Surfactants. J. Colloid Interface Sci. 1999, 215, 280-289. [CrossRef] [PubMed]

63. Kooli, F.; Liu, Y.; Abouddi, M.; Rakass, S.; OudgiriHassani, H.; Ibrahim, S.M.; Al-Faze, R. Application of organo-magadiites for the removal of eosin dye from aqueous solutions: Thermal treatment and regeneration. Molecules 2018, 23, 2280. [CrossRef] [PubMed]

64. Aksu, Z.; Tezer, S. Biosorption of reactive dyes on the green alga vulgaris. Process. Biochem. 2005, 40, 1361-1437. [CrossRef]

65. Andreo dos Santos, O.A.; Castelli, C.Z.; Oliveira, M.F.; de Almeida Neto, A.F.; da Silva, M.G.C. Adsorption of synthetic orange dye wastewater in organoclay. Chem. Eng. Trans. 2013, 32, 307-312.

66. Jovic-Jovicic, N.; Milutinovic-Nikolic, A.; Grzetic, I.; Jovanovic, D. Organobentonite as efficient textile dye sorbent. Chem. Eng. Technol. 2008, 31, 567-574. [CrossRef]

67. Ma, J.; Cui, B.; Li, D. Mechanism of adsorption of anionic dye from aqueous solutions onto organobentonite. J. Hazard. Mater. 2011, 186, 1758-1765. [CrossRef] [PubMed]

68. Onal, M.; Sarikaya, Y. Some physicochemical properties of partition nanophase formed in sorptive organoclays. Colloid Surf. A 2007, 296, 216-221. [CrossRef]

69. Kausar, A.; Iqbal, M.; Javed, A.; Aftab, K.; Nazli, Z.; Bhatti, H.N.; Nouren, S. Dyes adsorption using clay and modified clay: A review. J. Mol. Liq. 2018. [CrossRef]

70. Ozcan, A.; Oncu, E.M.; Ozcan, A.S. Adsoprtion of acid blue 193 from aqueous solutions onto DEDMA-sepiolite. J. Hazard. Mater. 2006, 129, 244-252. [CrossRef] [PubMed]

71. Senturk, H.B.; Ozdes, D.; Duran, C. Biosorption of Rhodamine 6G from aqueous solutions onto almond shell (Prunus dulcis) as a low cost biosorbent. Desalination 2010, 252, 81-87. [CrossRef]

72. Oyetade, O.A.; Nyamori, V.O.; Martincigh, B.S.; Jonnalagadda, S.B. Effectiveness of carbon nanotube-cobalt ferrite nanocomposites for the adsorption of rhodamine B from aqueous solutions. RSC Adv. 2015, 5, 22724-22739. [CrossRef]

73. Borisover, M.; Bukhanovsky, N.; Lapides, I.; Yariv, S. Mild pre-heating of organic cation-exchanged clays enhances their interactions with nitrobenzene in aqueous environment. Adsorption 2010, 16, $223-232$. [CrossRef]

74. Langmuir, I. The constitution and fundamental properties of solids and liquids. J. Am. Chem. Soc. 1916, 38, 2221-2295. [CrossRef]

75. Bello, O.S.; Olusegun, O.A.; Njoku, V.O. Fly ash: An alternative to powdered activated carbon for the removal of eosin dye from aqueous solutions. Bull. Chem. Soc. Ethiop. 2013, 27, 191-204. [CrossRef]

76. Thabet, M.S.; Ismaiel, A.M. Sol-gel $\gamma$-Al2O3 nanoparticles assessment of the removal of eosin yellow using: Adsoprtion, kinetic and thermodynamic parameters. J. Encapsulation Adsorpt. Sci. 2016, 6, 70-90. [CrossRef]

77. Shahadat, M.M.; Ismail, S. Regeneration performance of clay-based adsorbents for the removal of industrial dyes: A review. RSC Adv. 2018, 8, 24571-24587.

Sample Availability: Samples of the compounds are not available from the authors. 